\title{
Mechanisms of toluene removal in relation to the main components of biosyngas in a catalytic nonthermal plasma process
}

\author{
Bin $\mathrm{Xu}^{1,2}$, Jianjun $\mathrm{Xie}^{1 *}$, Xiuli Yin ${ }^{1}, \mathrm{Hao} \mathrm{Liu}^{3}$, Chenggong $\mathrm{Sun}^{3}$, Chuangzhi Wu ${ }^{1,2}$ \\ 1, CAS Key Laboratory of Renewable Energy, Guangdong Provincial Key Laboratory of New and Renewable Energy \\ Research and Development, Guangzhou Institute of Energy Conversion, Chinese Academy of Sciences, Guangzhou 510640, \\ China
}

2, University of Chinese Academy of Sciences, Beijing 100049, China

3, Department of Architecture and Built Environment, Faculty of Engineering, University of Nottingham, University Park Nottingham NG7 2RD UK

*Corresponding author: Tel.: +86 208705 7757. E-mail address: xiejj@ ms.giec.ac.cn (J. Xie).

Abstract: In this study, a packed-bed dielectric barrier discharge (DBD) reactor was built for the removal of biomass gasification tar. Two kinds of packing materials, glass pellets and a $\mathrm{Ni} / \gamma-\mathrm{Al}_{2} \mathrm{O}_{3}$ catalyst, were employed for the plasma alone process and the plasma catalytic process, respectively. Toluene was used as the tar surrogate, and five typical gas combinations, $\mathrm{N}_{2}, \mathrm{~N}_{2}+\mathrm{CO}_{2}, \mathrm{~N}_{2}+\mathrm{CO}_{2}+\mathrm{CO}, \mathrm{N}_{2}+\mathrm{CO}+\mathrm{H}_{2}$ and simulated gasification gas (SGG), were selected as carrier gases. The effects of the main components of the gasification gas on toluene removal under plasma and/or catalysis treatment were studied. The results indicated that the highest removal efficiency in the plasma alone process was achieved in the $\mathrm{N}_{2}$ atmosphere, and the addition of $\mathrm{H}_{2}, \mathrm{CO}$ or $\mathrm{CO}_{2}$ to the $\mathrm{N}_{2}$ led to a decrease in the removal performance. When $\mathrm{Ni} / \gamma-\mathrm{Al}_{2} \mathrm{O}_{3}$ was introduced into the plasma process, the best removal efficiency was obtained in the $\mathrm{N}_{2}+\mathrm{CO}_{2}$ atmosphere. However, the positive effect of $\mathrm{CO}_{2}$ on toluene removal switched to a negative effect when $\mathrm{CO}_{2}$ coexists with $\mathrm{CO}$ and $\mathrm{H}_{2}$ in the gas mixture. In addition, both the terminating effect at low temperature and the occurrence of methanation induced by $\mathrm{CO}$ at high temperature could significantly inhibit the removal of toluene in the plasma catalytic process. Typically, in the SGG atmosphere, the highest toluene removal efficiencies under plasma alone, catalysis alone and plasma catalysis treatment were $33.5 \%$, 38.6\% and $92.5 \%$, respectively. Furthermore, no $\mathrm{CN}$-containing or O-containing compounds were identified as major byproducts in the plasma catalytic process, which is significantly different from what was observed in the plasma alone process. Moreover, a detailed mechanism of the toluene removal under plasma and plasma catalysis treatment was proposed after analysis of gas and liquid products.

Key words: tar removal; nonthermal plasma; plasma catalytic process; toluene 


\section{Introduction}

Biomass, an important renewable energy source, can be converted into fuels and chemical products by physical, thermal and biological processes [1]. In terms of energy utilization efficiency and operational simplicity, biomass gasification may be one of the most promising technologies to convert biomass to a fuel gas or synthesis gas [2]. Fuel gas or synthesis gas can be used in numerous applications, such as gas engines, turbines, fuel cells and Fischer-Tropsch synthesis [3, 4]. However, the formation of undesirable byproducts/pollutants, such as NOx, fly ash and tar, during the gasification process is one of the toughest issues limiting the application of biomass gasification [5]. Tar is a complex mixture of condensable hydrocarbons, including monocyclic to polycyclic aromatic hydrocarbons and oxygen-containing compounds [6]. These compounds tend to condense when the process temperature is lower than its dew point, causing operational problems in downstream processes by blocking/clogging the filters and pipes [6,7]. Therefore, tar removal or cracking into light gaseous components is an essential step for the efficient use of raw fuel gas derived from biomass gasification.

Many purification methods have been used for tar removal in biomass gasification processes, including mechanical separation [7], thermal cracking [8] and catalytic reforming [9]. In addition to these common removal methods, the application of nonthermal plasma technology for tar removal has recently been explored. In a nonthermal plasma, although the gas temperature remains near room temperature, the temperature of the energetic electrons can reach $10^{4}-10^{5} \mathrm{~K}$, allowing them to easily break chemical bonds in reactive molecules and generate a variety of active species [10]. Because reactive molecules can be activated at low temperatures and ambient pressure, the application of nonthermal plasma technology has attracted considerable attention in the field of gaseous pollution control [11, 12]. Several studies have been conducted on tar removal using dielectric barrier discharge (DBD) [13-18], pulsed corona discharge [19, 20], gliding arc discharge [21-23] and microwave plasma [24-26]. Nonthermal plasma can efficiently eliminate tars or tar model compounds at low temperatures. Moreover, the combination of a catalyst and nonthermal plasma has the potential to further enhance the removal capability, reduce energy consumption and improve the selectivity for the desired products [27-29].

For a plasma process, the background gas is a very important factor as it exerts a significant effect on both the physical and chemical properties of the plasma, such as the discharge current and type and number of reactive components, causing variations in the reaction performances [30, 31]. Nair et al. [32] investigated the effect of different gas mixtures on naphthalene removal in a pulsed corona discharge reactor. They reported that naphthalene removal in a gasification gas atmosphere mainly occurred via oxidation reactions and that $\mathrm{CO}_{2}$ played an important role in this process, whereas $\mathrm{CO}$ was a strong inhibitor of this process because of the termination reaction with $\mathrm{O}$ radicals. Bityurin et al. [33] simulated the process of naphthalene 
removal through pulsed corona discharge. They found that the best removal performance was obtained in a pure $\mathrm{N}_{2}$ atmosphere, and the addition of $\mathrm{CO}_{2}, \mathrm{CO}$ or $\mathrm{H}_{2}$ to the $\mathrm{N}_{2}$ decreased the removal efficiency. Wnukowski et al. [24] used microwave plasma for benzene removal from a simulated biomass syngas. The results showed that the addition of $\mathrm{CO}_{2}$ or $\mathrm{H}_{2}$ to $\mathrm{N}_{2}$ resulted in removal efficiencies of $97 \%-98 \%$, while the addition of $\mathrm{CH}_{4}$ decreased the efficiency to $62 \%$ because of the reformation of benzene in the removal process. In addition to plasma process, for the catalytic destruction process, the gas atmosphere also plays an important role. Simell et al. [34] investigated the decomposition of toluene over different bed materials, such as $\mathrm{SiC}$, alumina, dolomite and a nickel catalyst, under single-component gases or mixed gas atmospheres. They reported that the predominant reaction of toluene removal over $\mathrm{SiC}$ and alumina was hydrocracking, and the toluene removal efficiency over calcined dolomite in a gasification gas atmosphere was lower than that in a $\mathrm{CO}_{2}$ or steam atmosphere due to the inhibitory effects of $\mathrm{CO}$ and $\mathrm{H}_{2}$. However, the rates of the toluene removal reactions in the gasification gas atmosphere seemed to be equal to that in the $\mathrm{CO}_{2}$ atmosphere when the $\mathrm{Ni} / \mathrm{Al}_{2} \mathrm{O}_{3}$ catalyst was adopted as the bed material. Devi et al. [35] studied the effect of the gas composition on naphthalene decomposition using pretreated olivine as the tar removal catalyst. They found that the naphthalene decomposition reactions were strongly affected by the concentrations of $\mathrm{H}_{2} \mathrm{O}, \mathrm{CO}_{2}$, and $\mathrm{H}_{2} ; \mathrm{CO}_{2}$ and $\mathrm{H}_{2} \mathrm{O}$ had positive effects, but $\mathrm{H}_{2}$ had an inhibitory effect. As a result, the gas composition influenced the reaction performance in both plasma processes and catalytic processes. Thus, the gas composition is likely to also exert an effect on tar removal in the plasma catalytic process. Moreover, the typical biomass gasification gas is mainly composed of $\mathrm{H}_{2}, \mathrm{CO}$, and $\mathrm{CO}_{2}$ with low quantities of $\mathrm{CH}_{4}$, and gaseous tar exists in such a gas atmosphere in the gasification process [36]. Due to the complexity of the components in gasification gas, one of the most challenging and important tasks is to determine the reaction mechanism of tar removal in the plasma and plasma catalysis processes. To address these challenges, the effects of the major gas components in gasification gas on tar removal must be understood. However, most previous studies on tar removal in plasma or plasma catalytic processes have used a noble gas such as nitrogen or helium as the carrier gas for tar, and literature on the influence of the gas composition is limited.

The present study aims to elucidate the effects of the major gas components of the gasification gas on tar removal under plasma and/or catalysis treatment. In this work, a coaxial packed-bed DBD reactor was designed and built for the removal of tar. Toluene was selected as a typical tar model compound because it is an important constituent of tar, and it has high thermal stability. Glass pellets and a $\mathrm{Ni} / \gamma-\mathrm{Al}_{2} \mathrm{O}_{3}$ catalyst were employed as packing materials for the plasma alone process and the plasma catalytic process, respectively. Since there are many possible combinations of the various components in gasification gas, five typical gas combinations, $\mathrm{N}_{2}, \mathrm{~N}_{2}+\mathrm{CO}_{2}, \mathrm{~N}_{2}+\mathrm{CO}_{2}+\mathrm{CO}, \mathrm{N}_{2}+\mathrm{CO}+\mathrm{H}_{2}$ and simulated gasification gas ( $\mathrm{SGG}$ ), were selected as carrier gases for this work based on relevant literature and our previous investigations [37]. SGG was adopted in this work to simulate the real biomass gasification product gas. $\mathrm{N}_{2}$ was the dominant component in the gasification gas, and 
the excited $\mathrm{N}_{2}$ molecules can be expected to be the most effective species for tar destruction; thus, pure $\mathrm{N}_{2}$ was selected as one of the carrier gases $[33,38]$. The presence of $\mathrm{CO}_{2}$ can provide $\mathrm{O}$ radicals in the plasma process, and the reaction of tar components and $\mathrm{O}$ radicals is regarded as one of the most important pathways for tar removal, so a $\mathrm{N}_{2}+\mathrm{CO}_{2}$ mixture was included [15, 32]. $\mathrm{CO}$ is regarded as the major terminating species for excited $\mathrm{N}_{2}$ molecules and can consume $\mathrm{O}$ radicals through a termolecular reaction, resulting in a substantial inhibitory effect on tar removal in plasma processes; thus, a $\mathrm{N}_{2}+\mathrm{CO}_{2}+\mathrm{CO}$ mixture was tested $[32,33,39]$. Our previous investigations showed that the methanation of $\mathrm{CO}$ had a significant effect on the gas composition and tar removal in plasma catalytic processes, and hence, the special gas mixture of $\mathrm{N}_{2}+\mathrm{CO}+\mathrm{H}_{2}$ was of great interest [37]. The toluene removal experiments were conducted in these typical gas mixtures under plasma alone, catalysis alone, and plasma catalysis treatment. Moreover, the exhaust gas and liquid products were analyzed quantitatively or qualitatively to clarify the reaction mechanism.

\section{Experimental}

\subsection{Catalyst preparation}

The $5 \mathrm{wt} \% \mathrm{Ni} / \gamma-\mathrm{Al}_{2} \mathrm{O}_{3}$ catalyst used in this work was prepared by a wet impregnation method. Commercial $\gamma-\mathrm{Al}_{2} \mathrm{O}_{3}$ pellets (diameter 2-4 mm) were calcined at $550{ }^{\circ} \mathrm{C}$ for $3 \mathrm{~h}$ in an air atmosphere prior to use. The appropriate weight of $\gamma-\mathrm{Al}_{2} \mathrm{O}_{3}$ was added to an aqueous solution of $\mathrm{Ni}\left(\mathrm{NO}_{3}\right)_{2} \cdot 6 \mathrm{H}_{2} \mathrm{O}$ and impregnated overnight at ambient temperature. The catalyst precursor was subsequently dried at $120^{\circ} \mathrm{C}$ for $6 \mathrm{~h}$ and then calcined at $400{ }^{\circ} \mathrm{C}$ for $4 \mathrm{~h}$ in an air atmosphere.

\subsection{Experimental setup}

A schematic diagram of the experimental setup is shown in Fig. 1. The DBD plasma reactor consisted of a cylindrical corundum ceramic tube (I.D.: $20 \mathrm{~mm}$, O.D.: $25 \mathrm{~mm}$ ) wrapped with 200-mm long stainless steel mesh as the outer electrode. A stainless steel rod (diameter $5 \mathrm{~mm}$ ), as the inner electrode, was placed along the axis of the tube. Therefore, the discharge gap was $7.5 \mathrm{~mm}$, and the corresponding discharge volume was $58.9 \mathrm{~mL}$. In the experiments, two packing materials, the $\mathrm{Ni} / \gamma$ $\mathrm{Al}_{2} \mathrm{O}_{3}$ catalysts and glass pellets (diameter $3 \mathrm{~mm}$ ), were placed directly in the discharge zone. To hold the packing materials, a stainless steel sieve plate was fixed at the end of the inner electrode $30 \mathrm{~mm}$ below the lower border of the discharge zone, and the region between the edge of the discharge zone and the stainless steel sieve was filled with quartz sand (diameter 1-2 $\mathrm{mm})$. The DBD reactor was vertically installed in a temperature-controlled tubular furnace. The reaction temperature was measured by a K-type thermocouple located on the exterior wall of the reactor tube at the midpoint of the discharge zone. When $\mathrm{Ni} / \gamma-\mathrm{Al}_{2} \mathrm{O}_{3}$ catalysts were selected as the packing material in the experiments, the catalysts were reduced in situ in flowing pure hydrogen stream at $400{ }^{\circ} \mathrm{C}$ for $2 \mathrm{~h}$ before each experiment. 
A dry nitrogen stream was introduced into a toluene bubbler that was submerged in a water bath kept at a constant temperature. The nitrogen stream containing gaseous toluene was then mixed with the carrier gas (five typical gas mixtures) in a mixing chamber before being fed into the reactor. A set of mass flow controllers (MFCs, Sevenstar, D07-series) was used to regulate the flow rates of the different gases. The total flow rate and the concentration of toluene were kept at $0.06 \mathrm{~m}^{3} / \mathrm{h}(\mathrm{based}$ on room temperature and atmospheric pressure $)$ and $600 \mathrm{ppmv}\left(2.2 \mathrm{~g} / \mathrm{m}^{3}\right)$, respectively, in this study. During the experiments, an ice trap consisting of two absorption bottles filled with $100 \mathrm{~mL}$ of hexane and placed in an ice water bath was placed at the exit of the reactor to collect the liquid products. Finally, the noncondensable gas products were collected in sampling gas bags.

The DBD reactor was connected to an AC high voltage power supply (Nanjing Suman, CTP-2000K) with a peak voltage of $30 \mathrm{kV}$ and a frequency of 5-20 kHz. The frequency was kept at $9 \mathrm{kHz}$ in this study. The high voltage applied to the reactor was measured with a high voltage probe (Tektronix, P6015A). A capacitor $(0.1 \mu \mathrm{F})$ was connected in series between the outer electrode of the reactor and the ground. The total charge was determined by measuring the voltage across the capacitor. The signals of the applied voltage and the charge were recorded with a digital oscilloscope (Tektronix, DPO2024B). The V-Q Lissajous method was used to determine the discharge power in the reactor. The discharge power of the DBD reactor was calculated by multiplying the area of the Lissajous diagram by the frequency.

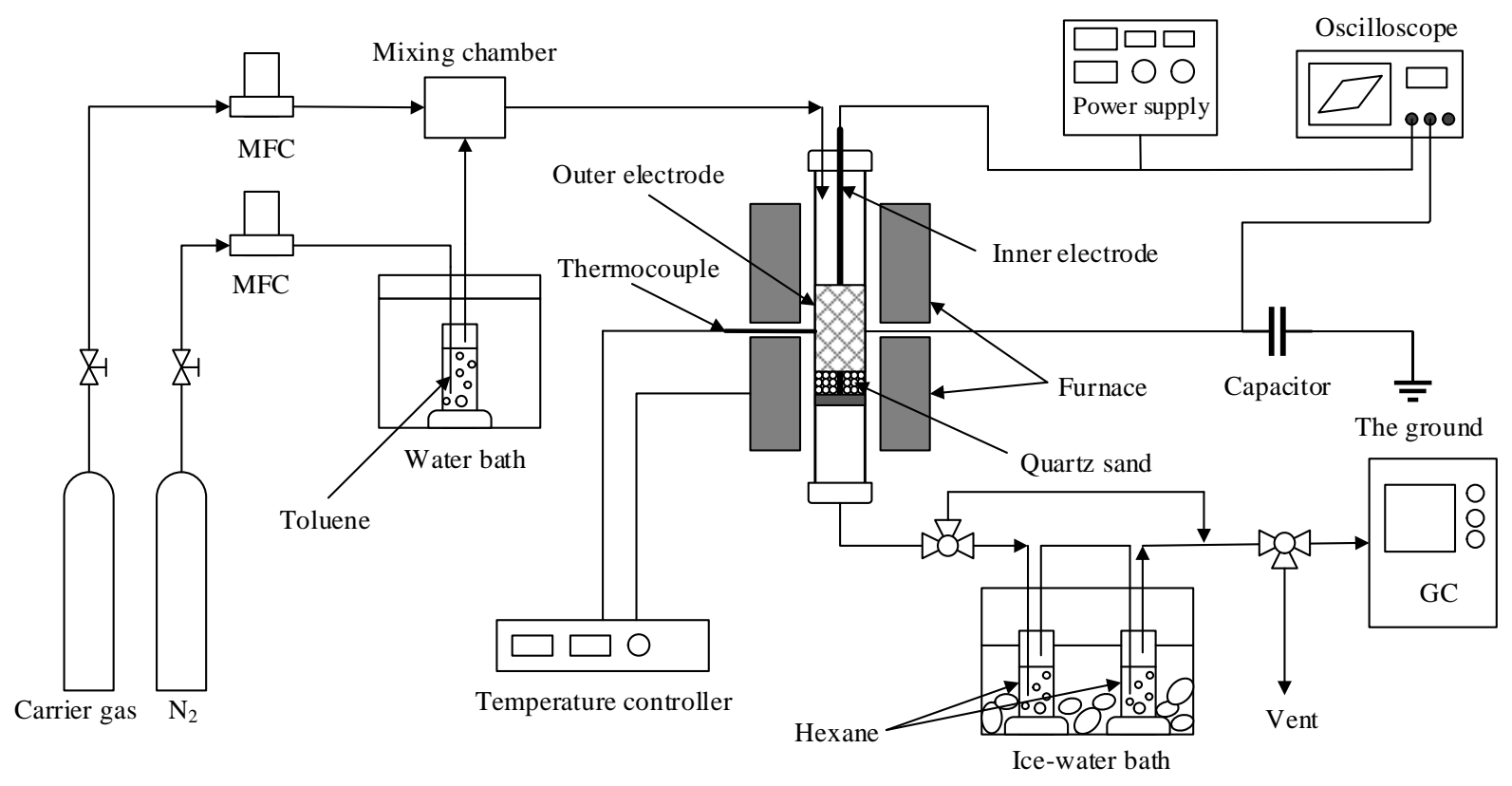

Fig. 1 Schematic of the experimental setup

\subsection{Methods of analysis}

The noncondensable gas products were analyzed by gas chromatography (GC, Agilent, GC490), and the chromatograph was 
equipped with two thermal conductivity detectors (TCDs) for the analysis of $\mathrm{N}_{2}, \mathrm{H}_{2}, \mathrm{CO}, \mathrm{CO}_{2}, \mathrm{CH}_{4}, \mathrm{C}_{2} \mathrm{H}_{2}, \mathrm{C}_{2} \mathrm{H}_{4}$ and $\mathrm{C}_{2} \mathrm{H}_{6}$. The concentrations of toluene and benzene (one of the products of toluene decomposition) were analyzed by another on-line gas chromatograph (Fuli, 9790) equipped with a flame ionization detector (FID). The liquid products dissolved in hexane were analyzed by an off-line gas chromatography-mass spectrometry instrument (GC-MS, Thermo Fisher, Trace 1300-ISQ). Further details on the GC and GC-MS measurements are presented in Table 1.

Table 1 GC and GC-MS analyses characteristic

\begin{tabular}{llllll}
\hline Apparatus & Sample & Detector & Column & Temperature & Detected component \\
\hline \multirow{2}{*}{ GC (Agilent, GC490) } & Gas & TCD & Molsieve5A & $120{ }^{\circ} \mathrm{C}$ & $\mathrm{H}_{2}, \mathrm{O}_{2}, \mathrm{~N}_{2}, \mathrm{CH}_{4}, \mathrm{CO}$ \\
& & TCD & PoraPlot Q & $80{ }^{\circ} \mathrm{C}$ & $\mathrm{CO}_{2}, \mathrm{C}_{2} \mathrm{H}_{2}, \mathrm{C}_{2} \mathrm{H}_{4}, \mathrm{C}_{2} \mathrm{H}_{6}$ \\
GC (Fuli, 9790) & Gas & FID & KB-FFAP & $80{ }^{\circ} \mathrm{C}$ & $\mathrm{C}_{7} \mathrm{H}_{8}, \mathrm{C}_{6} \mathrm{H}_{6}$ \\
GC-MS (Thermo & Liquid & MS & DB-5MS & $40{ }^{\circ} \mathrm{C}(4 \mathrm{~min}) \rightarrow\left[10^{\circ} \mathrm{C} / \mathrm{min}\right]$ & Liquid products \\
Fisher, Trace 1300-ISQ) & & & & $\rightarrow 300{ }^{\circ} \mathrm{C}(5 \mathrm{~min})$ & \\
\hline
\end{tabular}

The toluene removal efficiency and tar removal efficiency are defined as follows:

$\eta_{\text {toluene }}(\%)=\frac{[T]_{\text {in }}-[T]_{\text {out }}}{[T]_{\text {in }}} \times 100 \%$

$\eta_{\text {tar }}(\%)=\frac{[T]_{\text {in }}-\left([T]_{\text {out }}+[B]_{\text {out }}\right)}{[T]_{\text {in }}} \times 100 \%$

where $[T]_{\text {in }}$ and $[T]_{\text {out }}$ represent the concentrations of toluene at the inlet and the outlet of the reactor, respectively, and $[B]_{\text {out }}$ represents the concentration of benzene at the outlet. In our previous study, a high concentration of benzene, one of the major products, was detected in the plasma process [37]. Benzene is a typical component in tars and is not a desired product in the tar removal process. Thus, the method of assessing the tar removal efficiency adopted in this work evaluated the conversion of toluene into light-weight products rather than to another tar compound in the cleaning process. Considering the possible changes in the volumetric gas flow rate in the experiments, the changes in the $\mathrm{N}_{2}$ concentration were used to correct the concentrations of toluene and benzene measured at the outlet of the reactor.

The specific energy input (SEI) of the plasma discharge, i.e., the ratio of the input energy to the gas flow rate, is defined as follows:

$\mathrm{SEI}(\mathrm{J} / \mathrm{L})=\frac{P(W)}{Q(L / \min )} \times 60$

where $\mathrm{P}$ represents the discharge power, and $\mathrm{Q}$ is the gas flow rate.

All measurements were conducted after the reaction reached a stable state. After each experiment, the reactor was heated to $600{ }^{\circ} \mathrm{C}$ for $1 \mathrm{~h}$ in an air atmosphere to remove carbon deposits and other contaminants formed in the experiment.

3. Results and Discussion 


\subsection{Toluene removal by plasma alone}

The background gas has a significant effect on the reaction performance of the plasma process. Experiments to investigate the effects of different gas compositions on toluene removal were conducted at $200{ }^{\circ} \mathrm{C}$ with glass pellets as the packing material in a DBD reactor. Because glass pellets cannot catalyze toluene decomposition, the toluene removal in the reactor can be fully attributed to the plasma alone process at low temperatures. The experimental results are shown in Fig. 2, and the compositions of these gas mixtures utilized in this work are listed in Table 2.

Obviously, the toluene removal efficiency in the DBD reactor increases with SEI regardless of the gas mixture. For example, the toluene removal efficiency in the $\mathrm{N}_{2}$ atmosphere increased from $13.6 \%$ to $50.5 \%$ over the SEI range of $217-698 \mathrm{~J} / \mathrm{L}$, while in the $\mathrm{N}_{2}+\mathrm{CO}_{2}+\mathrm{CO}$ atmosphere, the efficiency increased from $4.5 \%$ to $31.8 \%$ as the SEI increased from 228 to $683 \mathrm{~J} / \mathrm{L}$. A higher SEI results in increased gas breakdown and more active species generated on the pellet surface and in the void spaces during a single discharge period, which facilitates the decomposition of toluene [40].

In a DBD plasma, various active species were generated by the collision of energetic electron and gas components, and these species then underwent numerous reactions, including toluene removal reactions and radical termination reactions. Moreover, the reaction between energetic electrons and toluene also occurred in this process. The important reactions occurring in this process are expected to be eqs. 4-13. For three-body collision processes, $M$ stands for the third body and can be any component in the SGG atmosphere $\left(\mathrm{N}_{2}, \mathrm{CO}_{2}, \mathrm{CO}, \mathrm{H}_{2}\right.$ or $\left.\mathrm{CH}_{4}\right)$. As shown in Fig. 2a, the toluene removal efficiencies were in the order $\mathrm{N}_{2}>\mathrm{N}_{2}+\mathrm{CO}_{2}>\mathrm{N}_{2}+\mathrm{CO}+\mathrm{H}_{2}>\mathrm{SGG}>\mathrm{N}_{2}+\mathrm{CO}_{2}+\mathrm{CO}$ atmosphere at the same SEI. In a pure $\mathrm{N}_{2}$ atmosphere, the excited $\mathrm{N}_{2}$ molecules $\left(\mathrm{N}_{2} *\right)$ generated via eq. 4 were the most effective active species for tar removal because of the high reaction rate of eq. 7 [33]. Although the addition of gases such as $\mathrm{CO}_{2}, \mathrm{H}_{2}$ and $\mathrm{CH}_{4}$ to the $\mathrm{N}_{2}$ can provide additional active species, such as $\mathrm{O}$ and $\mathrm{H}$ radicals (eqs. 5 and 6), the toluene removal reactions with these radicals are not as effective as those with $\mathrm{N}_{2} *$. Moreover, these active species generated in the plasma may also react with $\mathrm{N}_{2} *$ (eq. 11), decreasing the $\mathrm{N}_{2} *$ concentration. Therefore, the addition of other components to $\mathrm{N}_{2}$ is detrimental to the toluene removal process. $\mathrm{CO}$ was regarded as the main quencher of $\mathrm{N}_{2} *$ (eq. 12) in the gasification fuel gas; thus, the presence of $\mathrm{CO}$ in the carrier gas would significantly decrease the toluene removal efficiency [32]. In addition, the $\mathrm{O}$ radicals derived from $\mathrm{CO}_{2}$ are important active species for toluene removal (eq. 8) $[15,32]$. Therefore, the removal performance in the $\mathrm{N}_{2}+\mathrm{CO}_{2}$ atmosphere was better than that in gas mixtures containing $\mathrm{CO}$. The lowest toluene removal efficiency was observed in the $\mathrm{N}_{2}+\mathrm{CO}_{2}+\mathrm{CO}$ atmosphere, which can be attributed to a series of $\mathrm{N}_{2} *$ and $\mathrm{O}$ radicals termination reactions, including the termination of $\mathrm{N}_{2} *$ and $\mathrm{O}$ radicals with $\mathrm{CO}$ (eqs. 12 and 13) as well as the termination of $\mathrm{N}_{2} *$ with $\mathrm{O}$ radicals (eq. 11). For $\mathrm{N}_{2}+\mathrm{CO}+\mathrm{H}_{2}$ and the $\mathrm{SGG}$ atmosphere, the presence of $\mathrm{H}_{2}$ provides additional pathways for toluene removal through the reaction of $\mathrm{H}$ radicals and toluene (eq. 9), resulting in higher 
removal efficiencies than those observed with the $\mathrm{N}_{2}+\mathrm{CO}_{2}+\mathrm{CO}$ atmosphere [33]. The presence of $\mathrm{CO}_{2}$ caused the concentration of $\mathrm{N}_{2}$ in the $\mathrm{SGG}$ atmosphere to be lower than that in the $\mathrm{N}_{2}+\mathrm{CO}+\mathrm{H}_{2}$ atmosphere, leading to lower concentration of $\mathrm{N}_{2} *$. Moreover, the additional $\mathrm{O}$ radicals from $\mathrm{CO}_{2}$ cannot promote toluene removal because of the presence of $\mathrm{CO}$, which was confirmed by the fact that the lowest toluene removal efficiency was achieved in the $\mathrm{N}_{2}+\mathrm{CO}_{2}+\mathrm{CO}$ atmosphere. Therefore, the toluene removal efficiency in the SGG atmosphere was lower than that in the $\mathrm{N}_{2}+\mathrm{CO}+\mathrm{H}_{2}$ atmosphere.

Active species production:

$\mathrm{e}+\mathrm{N}_{2} \rightarrow \mathrm{N}_{2}^{*}+\mathrm{e}$

$\mathrm{e}+\mathrm{CO}_{2} \rightarrow \mathrm{CO}+\mathrm{O}+\mathrm{e}$

$\mathrm{e}+\mathrm{H}_{2} \rightarrow \mathrm{H}+\mathrm{H}+\mathrm{e}$

Toluene removal:

$\mathrm{N}_{2} *+\mathrm{C}_{7} \mathrm{H}_{8} \rightarrow$ Products

$\mathrm{O}+\mathrm{C}_{7} \mathrm{H}_{8} \rightarrow$ Products

$\mathrm{H}+\mathrm{C}_{7} \mathrm{H}_{8} \rightarrow$ Products

e $+\mathrm{C}_{7} \mathrm{H}_{8} \rightarrow$ Products

Radical termination:

$\mathrm{O}+\mathrm{N}_{2} * \rightarrow \mathrm{N}_{2}+\mathrm{O}$

$\mathrm{CO}+\mathrm{N}_{2} * \rightarrow \mathrm{N}_{2}+\mathrm{CO}$

$\mathrm{CO}+\mathrm{O}+\mathrm{M} \rightarrow \mathrm{CO}_{2}+\mathrm{M}$

Furthermore, Fig. 2a shows that the $\mathrm{N}_{2}+\mathrm{CO}_{2}$ and $\mathrm{N}_{2}+\mathrm{CO}+\mathrm{H}_{2}$ atmospheres had higher toluene removal efficiencies than the $\mathrm{N}_{2}$ atmosphere when the SEI was below $\sim 350 \mathrm{~J} / \mathrm{L}$. In eq. 4 , the excited $\mathrm{N}_{2}$ molecules $\left(\mathrm{N}_{2} *\right)$ can be either nitrogen metastable states, $\mathrm{N}_{2}\left(\mathrm{~A}^{3} \Sigma_{\mathrm{u}}^{+}\right)$, or the excited states, $\mathrm{N}_{2}\left(a^{\prime}\right)$ and $\mathrm{N}_{2}(B)$, in which $\mathrm{N}_{2}\left(\mathrm{~A}^{3} \Sigma_{\mathrm{u}}^{+}\right)$plays an important role in the cleaning process. The dissociation energies of $\mathrm{CO}_{2}$ and $\mathrm{H}_{2}$ are $5.45 \mathrm{eV}$ and $4.5 \mathrm{eV}$, respectively, which are lower than that of $\mathrm{N}_{2}\left(\mathrm{~A}^{3} \Sigma_{\mathrm{u}}^{+}\right)(6.17$ eV) $[38,41]$. The mean electron energy is low at low SEIs; thus, more $\mathrm{O}$ and $\mathrm{H}$ radicals can be generated than $\mathrm{N}_{2}\left(\mathrm{~A}^{3} \Sigma_{\mathrm{u}}^{+}\right)$ under these conditions. The higher concentrations of $\mathrm{O}$ and $\mathrm{H}$ radicals can provide a better removal performance, although they are not as effective as $\mathrm{N}_{2}\left(\mathrm{~A}^{3} \Sigma_{\mathrm{u}}^{+}\right)$. Therefore, the removal efficiencies in both $\mathrm{N}_{2}+\mathrm{CO}_{2}$ and $\mathrm{N}_{2}+\mathrm{CO}+\mathrm{H}_{2}$ atmospheres are higher than that in the $\mathrm{N}_{2}$ atmosphere at low SEI. 
Fig. $2 b$ shows the effects of the gas composition on the tar removal efficiency in the DBD reactor with glass pellets as the packing material. Due to the production of low concentrations of benzene in the toluene removal process under plasma treatment, the tar removal efficiencies were slightly lower than the toluene removal efficiencies for all gas mixtures, as shown in Fig. 2. Furthermore, we found that the concentrations of benzene generated under the different gas mixtures and SEI values were similar. Thus, it can be concluded that the gas composition and discharge power (SEI) had no significant effect on benzene production in the plasma alone process.

Table 2 Composition of each gas mixture used in this work

\begin{tabular}{llllll}
\hline Gas mixture & $\mathrm{N}_{2}$ vol $\%$ & $\mathrm{H}_{2}$ vol $\%$ & $\mathrm{CO}$ vol $\%$ & $\mathrm{CO}_{2}$ vol \% & $\mathrm{CH}_{4}$ vol \% \\
\hline $\mathrm{N}_{2}$ & 100 & 0 & 0 & 0 & 0 \\
$\mathrm{~N}_{2}+\mathrm{CO}_{2}$ & 88 & 0 & 0 & 12 & 0 \\
$\mathrm{~N}_{2}+\mathrm{CO}_{2}+\mathrm{CO}$ & 70 & 0 & 18 & 12 & 0 \\
$\mathrm{~N}_{2}+\mathrm{CO}+\mathrm{H}_{2}$ & 67 & 15 & 18 & 0 & 0 \\
$\mathrm{SGG}$ & 53.5 & 15 & 18 & 12 & 1.5 \\
\hline
\end{tabular}
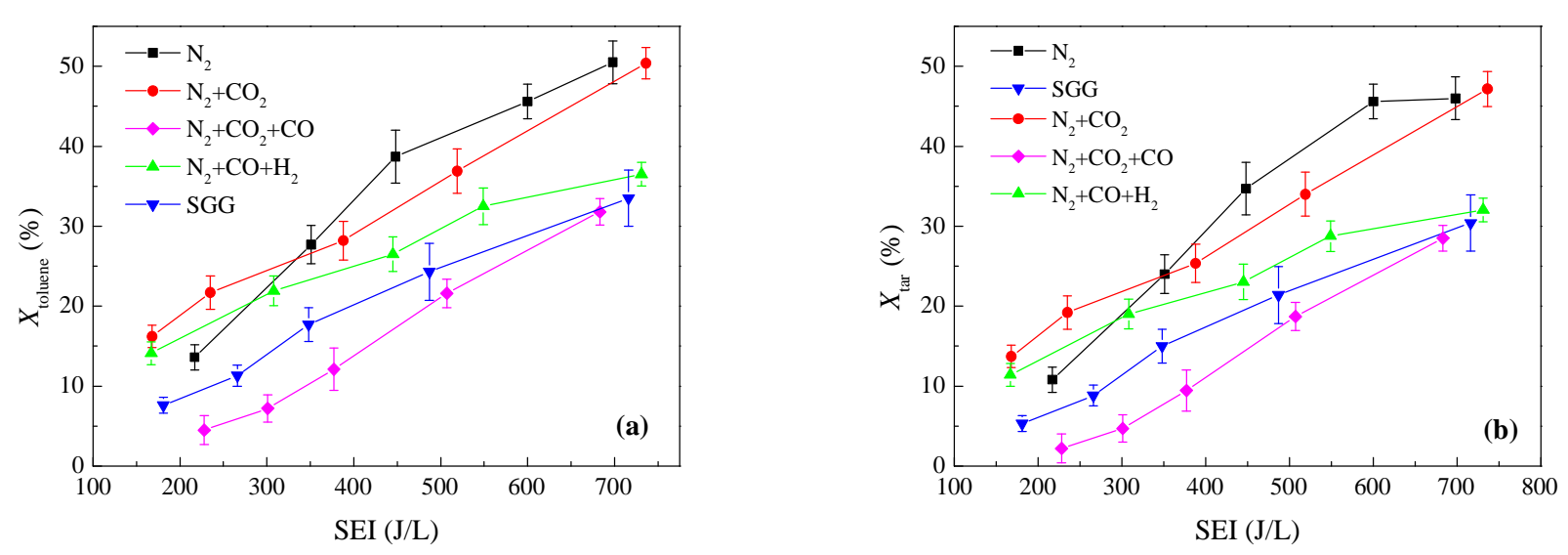

Fig. 2 Effect of the gas composition on the toluene removal efficiency (a) and the tar removal efficiency (b) as a function of specific energy input in the plasma alone process (reaction conditions: total gas flow rate $=0.06 \mathrm{~m}^{3} / \mathrm{h}$, reaction temperature $=$ $200{ }^{\circ} \mathrm{C}$, and toluene concentration $=600 \mathrm{ppmv}$ )

\subsection{Toluene removal by plasma catalysis at $200{ }^{\circ} \mathrm{C}$}

The introduction of a catalyst to the nonthermal plasma process was expected to be a promising method to enhance the removal performance and improve the selectivity for the desired products by combining the advantages of nonthermal plasma and catalysis [27]. To investigate the effects of the gas composition on the toluene removal in the plasma catalytic process and compare those results with those obtained from the plasma alone process, the experiments in this section were conducted at 
$200{ }^{\circ} \mathrm{C}$ with a Ni/ $\gamma-\mathrm{Al}_{2} \mathrm{O}_{3}$ catalyst as the packing material in the DBD reactor, and the results are shown in Fig. 3.

As shown in Fig. 3a, the toluene removal efficiency increased with increasing SEI for all gas mixtures. The maximum value $(89.1 \%)$ was obtained in the $\mathrm{N}_{2}+\mathrm{CO}_{2}$ atmosphere at $768 \mathrm{~J} / \mathrm{L}$, and the minimum value $(26.7 \%)$ was achieved in the $\mathrm{N}_{2}+\mathrm{CO}+\mathrm{H}_{2}$ atmosphere at $209 \mathrm{~J} / \mathrm{L}$. Moreover, the toluene removal efficiencies in the plasma catalytic process were higher than those in the plasma alone process (Fig. 2a) for all gas mixtures, which were mostly attributed to the specific characteristics of the different packing materials. Compared to the glass pellets, $\mathrm{Ni} / \gamma-\mathrm{Al}_{2} \mathrm{O}_{3}$ possess a higher permittivity, specific surface area and pore volume [37]. Its higher permittivity allows it to store more energy in a single discharge period and accelerate the plasmachemical process, and its larger specific surface area and pore volume allows it to absorb more toluene and prolong the residence time, which facilitate the removal of toluene [40].

However, the catalytic effects cannot be ignored. Typically, the role of a catalyst in a given process is to lower the activation energy and regulate the selectivity for the desired products. Indeed, this function also applies to the plasma catalytic process [42]. As shown in Fig. 3a, the toluene removal efficiencies were in the order $\mathrm{N}_{2}+\mathrm{CO}_{2}>\mathrm{N}_{2}>\mathrm{N}_{2}+\mathrm{CO}_{2}+\mathrm{CO}>\mathrm{SGG}>\mathrm{N}_{2}+$ $\mathrm{CO}+\mathrm{H}_{2}$ atmosphere at the same $\mathrm{SEI}$ in the plasma catalytic process. Clearly, the gas mixtures containing $\mathrm{CO}_{2}, \mathrm{such}$ as $\mathrm{N}_{2}+\mathrm{CO}_{2}$ and $\mathrm{N}_{2}+\mathrm{CO}_{2}+\mathrm{CO}$ atmospheres, provided higher toluene removal efficiencies. In the plasma alone process, the toluene destruction is dominated by plasma gas-phase chemistry, and the presence of $\mathrm{CO}_{2}$ cannot have a positive effect on toluene removal because of the various termination reactions (eqs. 11-13). However, in the plasma catalytic process, in addition to the gas-phase chemical reactions, the toluene can also be removed by surface reactions due to the inclusion of a catalyst. The absorbed toluene can selectively react with active species to form products. Although the dissociative adsorption of $\mathrm{CO}_{2}$ onto a catalyst surface is difficult at low temperatures, the plasma can dissociate the reactant molecules in the gas phase before adsorption, making the adsorption step easier[43]. The additional surface reactions between toluene and the active species derived from $\mathrm{CO}_{2}$ plasma activation improve the toluene removal efficiency in these gas mixtures containing $\mathrm{CO}_{2}$.

Furthermore, compared to the plasma alone processes, the presence of $\mathrm{CO}$ in the gas mixture had a greater influence on toluene removal in the plasma catalytic process, and it caused a significant decrease in the toluene removal efficiency. For example, the difference in the toluene removal efficiencies observed with the $\mathrm{N}_{2}+\mathrm{CO}_{2}$ and $\mathrm{N}_{2}+\mathrm{CO}_{2}+\mathrm{CO}$ atmospheres under plasma alone treatment was $15.3 \%$ at an SEI of $500 \mathrm{~J} / \mathrm{L}$, while under plasma catalysis treatment at the same SEI, the difference was $37.7 \%$. Apart from the terminating effect induced by $\mathrm{CO}$ in the gas phase, the substantial inhibitory effect of $\mathrm{CO}$ can be partly attributed to the competitive adsorption of the reactants and gas components. The adsorption of reactants is essential in a catalytic process. When $\mathrm{CO}$ was present in the gas mixture, the large proportion of active sites on the catalyst surface that 
were occupied by $\mathrm{CO}$ severely inhibited the adsorption of toluene and other active species generated in the plasma process. Thus, the reduced reactants adsorption probability weakened the positive effect of the catalyst, leading to the decrease in the toluene removal efficiency. Furthermore, as shown in Fig. 3a, the values of the toluene removal efficiencies of the gas mixtures containing $\mathrm{CO}$ were similar to each other, which suggested that other gas components, such as $\mathrm{H}_{2}$ and $\mathrm{CH}_{4}$, had no significant effects on toluene removal in the plasma catalytic process at $200{ }^{\circ} \mathrm{C}$.

Fig. $3 \mathrm{~b}$ shows the effects of the gas composition on the tar removal efficiency in the plasma catalytic process at $200{ }^{\circ} \mathrm{C}$. Due to the formation of benzene at low concentrations in the toluene decomposition process, the tar removal efficiency was lower than the toluene removal efficiency for all gas mixtures. In addition, a comparison of Fig. 3a and $3 \mathrm{~b}$ suggests that the gas compositions and discharge power did not substantially influence the benzene production, which was consistent with the results obtained in the plasma alone process.
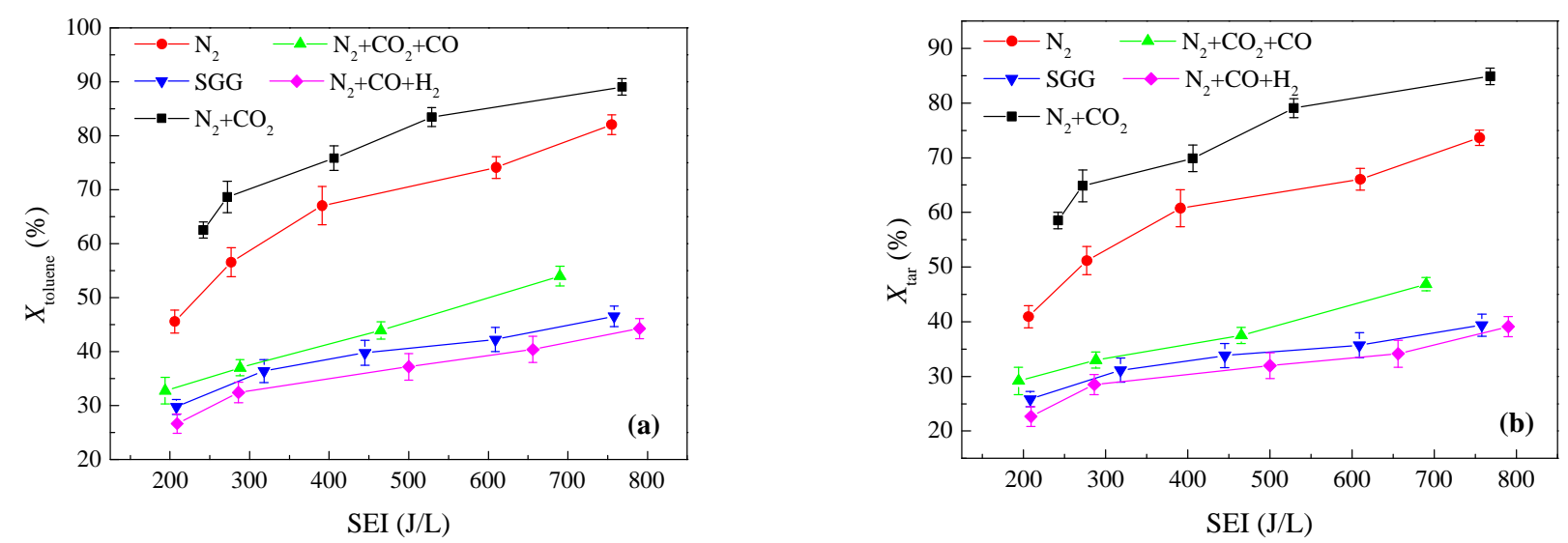

Fig. 3 Effects of gas composition on the toluene removal efficiency (a) and tar removal efficiency (b) as a function of specific energy input in the plasma catalytic process (reaction conditions: total gas flow rate $=0.06 \mathrm{~m}^{3} / \mathrm{h}, \mathrm{reaction}$ temperature $=200{ }^{\circ} \mathrm{C}$, and toluene concentration $=600 \mathrm{ppmv}$ )

\subsection{Toluene removal by plasma catalysis at higher temperatures}

\subsubsection{Catalysis alone}

As shown in Fig. 3a, although the desired removal performance was achieved in some gas mixtures, such as $\mathrm{N}_{2}$ and $\mathrm{N}_{2}+\mathrm{CO}_{2}$ atmospheres, the maximum toluene removal efficiency in the SGG atmosphere was as low as $46.5 \%$ at $758 \mathrm{~J} / \mathrm{L}$. The results indicate that the combination of $\mathrm{DBD}$ plasma and the $\mathrm{Ni} / \gamma-\mathrm{Al}_{2} \mathrm{O}_{3}$ catalyst cannot effectively remove toluene in the SGG atmosphere at temperatures as low as $200{ }^{\circ} \mathrm{C}$ even at a high discharge power. Previous studies showed that increasing the reaction temperature could enhance the removal capacity of the plasma catalytic process and hence achieve the desired 
removal performance at a lower energy input $[37,44]$. Thus, in this section, the toluene removal experiments with plasma catalysis were conducted at higher temperatures, and the effects of the gas composition on the removal performance under these conditions were investigated. Catalysis plays an important role in pollutant destruction in plasma catalytic processes at high temperatures. Therefore, as a comparison, the removal of toluene using the $\mathrm{Ni} / \gamma-\mathrm{Al}_{2} \mathrm{O}_{3}$ catalyst alone was conducted to elucidate the plasma catalysis mechanism.

Due to the complex composition of the gasification fuel gas and the presence of the catalyst, the reaction network of the catalytic degradation of toluene consisted of many competing and parallel reactions [34]. The main reactions are as follows:

Catalytic cracking reaction:

$\mathrm{C}_{7} \mathrm{H}_{8} \rightarrow \mathrm{C}+\mathrm{H}_{2}+\mathrm{CH}_{4}+\mathrm{C}_{2} \mathrm{H}_{4}+\mathrm{C}_{n} \mathrm{H}_{m}+\ldots$

Dry reforming reaction:

$\mathrm{C}_{7} \mathrm{H}_{8}+7 \mathrm{CO}_{2} \rightarrow 14 \mathrm{CO}+4 \mathrm{H}_{2}$

Methanation reaction:

$\mathrm{CO}+3 \mathrm{H}_{2} \rightarrow \mathrm{CH}_{4}+\mathrm{H}_{2} \mathrm{O}$

Water-gas shift reaction:

$\mathrm{CO}+\mathrm{H}_{2} \mathrm{O} \rightarrow \mathrm{H}_{2}+\mathrm{CO}_{2}$

CO disproportion reaction:

$2 \mathrm{CO} \rightarrow \mathrm{C}+\mathrm{CO}_{2}$

Fig. 4 shows the results of the toluene removal experiments via the catalytic destruction process under different gas mixtures. As shown in Fig. 4a, higher reaction temperatures favored the removal of toluene, and the toluene removal efficiencies of all the gas mixtures reached their maxima at $400{ }^{\circ} \mathrm{C}$. The $\mathrm{N}_{2}, \mathrm{~N}_{2}+\mathrm{CO}_{2}$ and $\mathrm{N}_{2}+\mathrm{CO}_{2}+\mathrm{CO}$ atmospheres provided nearly $100 \%$ toluene removal efficiency at $400{ }^{\circ} \mathrm{C}$, while the maxima in the $\mathrm{N}_{2}+\mathrm{CO}+\mathrm{H}_{2}$ and $\mathrm{SGG}$ atmospheres were merely $50.2 \%$ and $32.7 \%$, respectively, at the same temperature. The toluene removal efficiency in a pure $\mathrm{N}_{2}$ atmosphere gradually increased with increasing temperature and provided a higher removal performance at low temperatures relative to the other gas mixtures. The addition of $\mathrm{N}_{2}$ to the other gas components, such as $\mathrm{CO}_{2}$ and $\mathrm{CO}$, changed the toluene removal behavior. For example, the addition of $\mathrm{CO}_{2}$ improved the removal efficiency at high temperatures, but an inhibitory effect was observed as the temperature fell below $300{ }^{\circ} \mathrm{C}$. In addition, in the $\mathrm{N}_{2}+\mathrm{CO}_{2}+\mathrm{CO}$ atmosphere, toluene degradation did not occur until the reaction temperature was above the threshold value $300{ }^{\circ} \mathrm{C}$, while in the $\mathrm{N}_{2}+\mathrm{CO}+\mathrm{H}_{2}$ and $\mathrm{SGG}$ atmospheres, the threshold 
temperature was $350{ }^{\circ} \mathrm{C}$.

In the $\mathrm{N}_{2}+\mathrm{CO}_{2}$ atmosphere, the competitive adsorption between toluene and $\mathrm{CO}_{2}$ inhibited the removal of toluene via eq. 14 at low temperatures. However, as the reaction rate of eq. 15 increased with increasing temperature, the dry reforming reaction, the more effective toluene removal pathway, became more important in the process; thus, the $\mathrm{N}_{2}+\mathrm{CO}_{2}$ atmosphere achieved a higher toluene removal efficiency than the pure $\mathrm{N}_{2}$ atmosphere at high temperatures [45]. For the gas mixtures containing $\mathrm{CO}$, toluene removal efficiencies of less than $10 \%$ were obtained when the temperature was below $300{ }^{\circ} \mathrm{C}$. By comparing this to the removal performance in a pure $\mathrm{N}_{2}$ atmosphere, we can conclude that the adsorption of $\mathrm{CO}$ on the catalyst surface was stronger than the binding of toluene. Furthermore, as shown in Fig. 4a, there was a significant increase in the toluene removal efficiency in the CO-containing gas mixtures as the reaction temperature reached a threshold value. This trend can be explained as follows: at low temperatures, the active sites on the catalyst surface were blocked by the adsorbed CO molecules, inhibiting the adsorption of toluene. At high temperatures, the reactions involving $\mathrm{CO}$, such as $\mathrm{CO}$ disproportion (eq. 18), are accelerated, and regenerating more active sites after product desorption over a given period, which allows more opportunities for toluene to be adsorbed on active sites, although competitive adsorption with other gas components still occurs. Fig. 5 shows the concentration changes of the major gas components as a function of reaction temperature under catalysis alone treatments. Fig. 5a shows the concentrations of the gas components at the reactor outlet in the $\mathrm{N}_{2}+\mathrm{CO}_{2}+\mathrm{CO}$ atmosphere. The concentration of $\mathrm{CO}_{2}$ greatly increased when the temperature was above $300{ }^{\circ} \mathrm{C}$, indicating that the disproportion reaction was significantly accelerated in this temperature range. Obviously, the threshold temperature for the rapid acceleration of the disproportion reaction is consistent with that for the significant increase in the toluene removal efficiency in the $\mathrm{N}_{2}+\mathrm{CO}_{2}+\mathrm{CO}$ atmosphere. For the $\mathrm{N}_{2}+\mathrm{CO}+\mathrm{H}_{2}$ and $\mathrm{SGG}$ atmospheres, due to the additional competitive reactions, including methanation (eq. 16) and the water-gas shift reaction (eq. 17), the competitive adsorption of these reactants, such as $\mathrm{H}_{2}$ and $\mathrm{H}_{2} \mathrm{O}$, decreased the adsorption of toluene on the catalyst surface after product desorption, increasing the threshold temperature to $350{ }^{\circ} \mathrm{C}$.

Notably, the toluene removal efficiency in the $\mathrm{N}_{2}+\mathrm{CO}+\mathrm{H}_{2}$ atmosphere was higher than that in the SGG atmosphere at $400{ }^{\circ} \mathrm{C}$. In the SGG atmosphere, the methanation, water-gas shift and disproportion reactions might be suppressed because $\mathrm{CH}_{4}$ and $\mathrm{CO}_{2}$ were products of these reactions (eqs. 16-18). Thus, the consumption of $\mathrm{CO}$ was also suppressed, and its concentration in the SGG atmosphere should be higher than that in the $\mathrm{N}_{2}+\mathrm{CO}+\mathrm{H}_{2}$ atmosphere. Fig. $5 \mathrm{~b}$ and Fig. $5 \mathrm{c}$ show the changes in the concentrations of the gas components in the $\mathrm{N}_{2}+\mathrm{CO}+\mathrm{H}_{2}$ atmosphere and in the SGG atmosphere, respectively. At $400{ }^{\circ} \mathrm{C}$, the concentrations of $\mathrm{CO}$ and $\mathrm{H}_{2}$ in the $\mathrm{N}_{2}+\mathrm{CO}+\mathrm{H}_{2}$ atmosphere reached minimum values of $8.3 \%$ and $10.6 \%$, respectively. In the SGG atmosphere, the concentrations of $\mathrm{CO}$ and $\mathrm{H}_{2}$ were $13.6 \%$ and $9.9 \%$, respectively, at the same temperature. Clearly, the sum of the concentrations of $\mathrm{CO}$ and $\mathrm{H}_{2}$ in the SGG atmosphere was higher than that in the $\mathrm{N}_{2}+\mathrm{CO}+\mathrm{H}_{2}$ atmosphere, and 
because these gases can inhibit the adsorption of toluene on the catalyst surface, this leads to a lower toluene removal efficiency in the SGG atmosphere.

Fig. $4 \mathrm{~b}$ shows the effects of gas compositions on the tar removal efficiency in the catalysis alone process. As shown in Fig. $4 \mathrm{~b}$, for the $\mathrm{N}_{2}, \mathrm{~N}_{2}+\mathrm{CO}_{2}$ and $\mathrm{N}_{2}+\mathrm{CO}_{2}+\mathrm{CO}$ atmospheres, the removal behaviors of tar were similar to those of toluene, and tar removal efficiencies of nearly $100 \%$ were obtained at $400{ }^{\circ} \mathrm{C}$. However, in the $\mathrm{N}_{2}+\mathrm{CO}+\mathrm{H}_{2}$ and SGG atmospheres, the tar removal efficiencies were still less than $15 \%$ even when the temperature was increased to $400{ }^{\circ} \mathrm{C}$; this implies that most of the removed toluene was converted to benzene, which was more difficult to decompose than toluene.
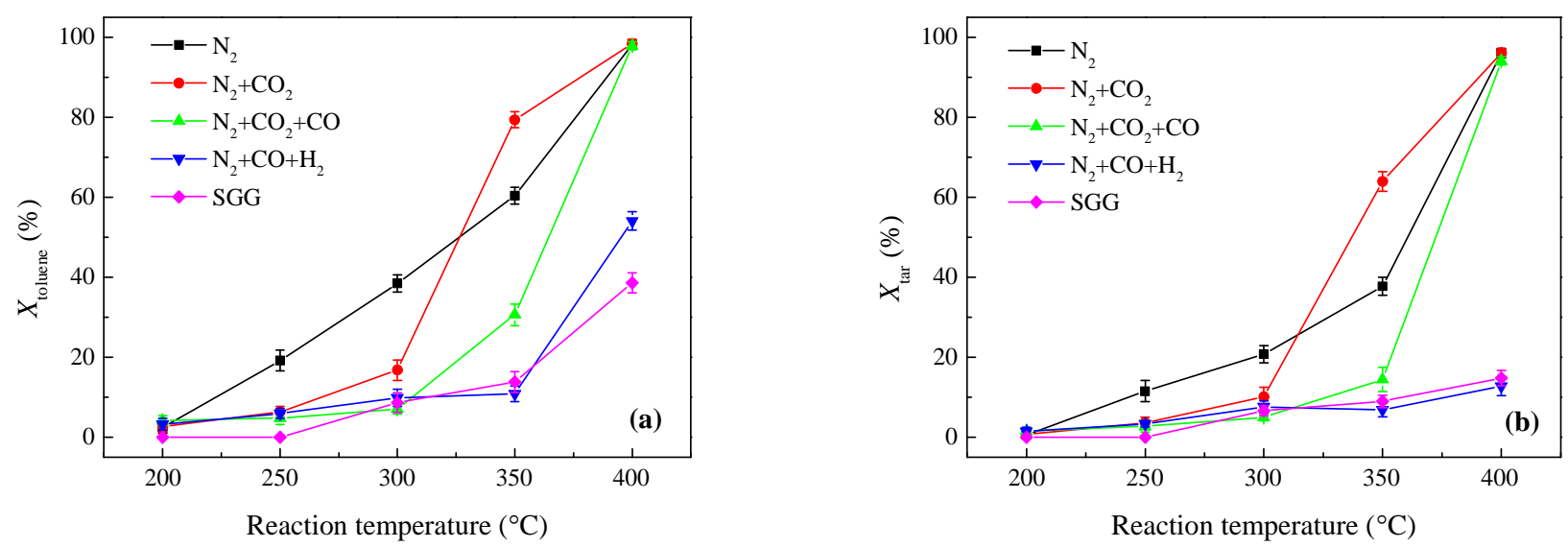

Fig. 4 Effects of gas composition on the toluene removal efficiency (a) and tar removal efficiency (b) as a function of reaction temperature in the catalyst alone process (reaction conditions: total gas flow rate $=0.06 \mathrm{~m}^{3} / \mathrm{h}$ and toluene concentration $=600 \mathrm{ppmv}$ )

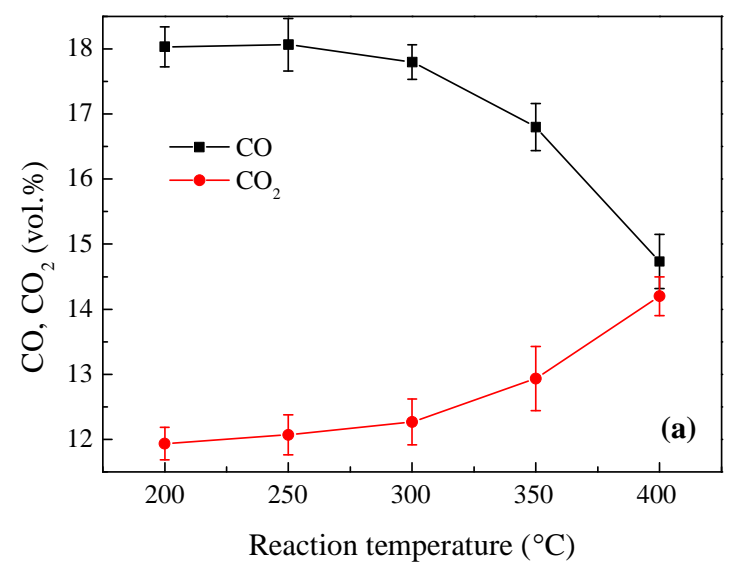



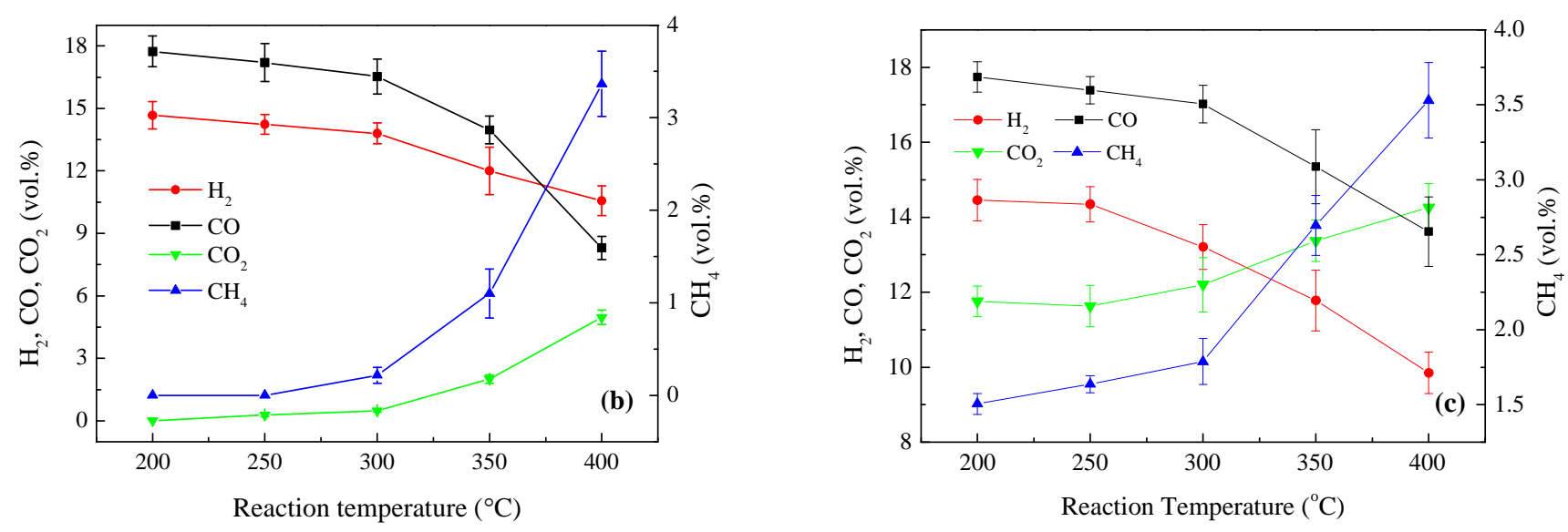

Fig. 5 Concentrations of the main gas components at the outlet under $\mathrm{N}_{2}+\mathrm{CO}_{2}+\mathrm{CO}$ (a), $\mathrm{N}_{2}+\mathrm{CO}+\mathrm{H}_{2}$ (b) and SGG (c) atmospheres as a function of reaction temperature in the catalyst alone process (reaction conditions: total gas flow rate $=0.06 \mathrm{~m}^{3} / \mathrm{h}$ and toluene concentration $=600 \mathrm{ppmv}$ )

\subsubsection{Plasma catalysis}

The removal of toluene under different gas mixtures in the plasma catalytic process was evaluated in the temperature range of $200-400{ }^{\circ} \mathrm{C}$, and the results are shown in Fig. 6. For all gas mixtures, within the temperature range of $200-400{ }^{\circ} \mathrm{C}$, the toluene removal efficiencies first decreased, reaching their minimum values, and then increased with increasing temperature to reach their maximum values at $400{ }^{\circ} \mathrm{C}$. The $\mathrm{N}_{2}, \mathrm{~N}_{2}+\mathrm{CO}_{2}$ and $\mathrm{N}_{2}+\mathrm{CO}_{2}+\mathrm{CO}$ atmospheres reached their lowest toluene removal efficiencies $\left(50.0 \%, 61.9 \%\right.$ and $31.7 \%$, respectively) at $250{ }^{\circ} \mathrm{C}$, while the minimum values for the $\mathrm{N}_{2}+\mathrm{CO}+\mathrm{H}_{2}$ and SGG atmospheres $\left(19.9 \%\right.$ and $24.5 \%$, respectively) were observed at $300^{\circ} \mathrm{C}$. At $400^{\circ} \mathrm{C}$, the toluene removal efficiency in SGG was $92.5 \%$, and those in the other gas mixtures were close to $100 \%$.

In a plasma catalytic process, pollutant destruction is dominated by plasma gas-phase chemistry and shows a strong dependence on the plasma intensity at low temperatures [43]. Increasing the temperature had a negative effect on the plasma intensity, resulting in a decrease in the toluene removal efficiency in all gas mixtures at low temperatures [37]. With increasing reaction temperature, the thermal activation of the catalyst becomes important in the cleaning process, increasing the toluene removal efficiency, as shown in Fig. 4. Moreover, due to the presence of plasma, the combination of the plasma and the catalyst can generate a synergetic effect when the reaction temperature is above a threshold temperature, which can greatly enhance the removal performance of this process [37]. Thus, the toluene removal efficiencies significantly increase with increasing reaction temperature after reaching the lowest values for all gas mixtures.

Compared to the catalyst alone process, the introduction of plasma improved the toluene removal performance of the catalytic 
process. For the $\mathrm{N}_{2}, \mathrm{~N}_{2}+\mathrm{CO}_{2}$ and $\mathrm{N}_{2}+\mathrm{CO}_{2}+\mathrm{CO}$ atmospheres, the enhancements in the toluene removal efficiencies induced by the introduction of plasma were most apparent in the low temperature range $\left(<350{ }^{\circ} \mathrm{C}\right)$. For the $\mathrm{N}_{2}+\mathrm{CO}+\mathrm{H}_{2}$ and $\mathrm{SGG}$ atmospheres, obvious enhancements can be observed when the temperature was above $350{ }^{\circ} \mathrm{C}$. Typically, at $400{ }^{\circ} \mathrm{C}, 44.6 \%$ and $53.9 \%$ increases in the toluene removal efficiencies were achieved in the plasma catalytic process for the $\mathrm{N}_{2}+\mathrm{CO}+\mathrm{H}_{2}$ and SGG atmospheres, respectively, compared using the catalyst alone. Obviously, the toluene in the gasification fuel gas can be effectively removed by the combination of plasma and a catalyst. Furthermore, in addition to the enhancement in the toluene removal reactions, other reactions occurring in the catalytic process were also enhanced by the introduction of the plasma. Fig. 7 shows the concentration changes of the main gas components in the $\mathrm{N}_{2}+\mathrm{CO}+\mathrm{H}_{2}$ and SGG atmospheres with increasing temperature. The changes in the concentrations of gas components under these two gas mixtures were attributed to the occurrence of a series of reactions, including methanation, water-gas shift and disproportion reactions. By comparing Fig. 5 and Fig. 7, the rates of the changes in the main gas components in the plasma catalytic process were greater than those in the catalyst alone processes, which means that these related reactions were enhanced by the introduction of plasma.

As shown in Fig. 6a, the presence of $\mathrm{CO}_{2}$ in the gas mixtures appears to facilitate the removal of toluene. For example, the toluene removal efficiency in the $\mathrm{N}_{2}+\mathrm{CO}_{2}$ atmosphere showed the highest values among these gas mixtures throughout the temperature range of $200-400{ }^{\circ} \mathrm{C}$. In addition, the $\mathrm{N}_{2}+\mathrm{CO}_{2}+\mathrm{CO}$ atmosphere achieved a higher removal efficiency than the pure $\mathrm{N}_{2}$ atmosphere when the temperature was above $350{ }^{\circ} \mathrm{C}$. This facilitation can be attributed to the fact that the active species generated by the interaction between $\mathrm{CO}_{2}$ and plasma accelerates the toluene removal reactions in the presence of a catalyst [43]. However, when $\mathrm{CO}_{2}$ coexisted with $\mathrm{CO}$ and $\mathrm{H}_{2}$ in the gas mixture, the positive effect of $\mathrm{CO}_{2}$ on toluene removal was suppressed, and conversely, the toluene removal efficiencies in the gas mixtures containing $\mathrm{CO}_{2}$ were lower than in those without $\mathrm{CO}_{2}$. Fig. 6a shows that the toluene removal efficiency in the SGG atmosphere was slightly lower than that in the $\mathrm{N}_{2}+\mathrm{CO}+\mathrm{H}_{2}$ atmosphere at $400{ }^{\circ} \mathrm{C}$. Moreover, this trend was more apparent in the tar removal efficiency at the same temperature (Fig. 6b). A similar phenomenon was observed when using the catalyst alone. The concentrations of $\mathrm{CO}$ and $\mathrm{H}_{2}$ in the SGG atmosphere were higher than those in the $\mathrm{N}_{2}+\mathrm{CO}+\mathrm{H}_{2}$ atmosphere at $400{ }^{\circ} \mathrm{C}$, as shown in Fig. 7 . The high concentrations of $\mathrm{CO}$ and $\mathrm{H}_{2}$ inhibited the adsorption of toluene and benzene on the catalyst surface, leading to lower toluene/tar removal efficiencies at $400{ }^{\circ} \mathrm{C}$ in the $\mathrm{SGG}$ atmosphere compared to those in the $\mathrm{N}_{2}+\mathrm{CO}+\mathrm{H}_{2}$ atmosphere.

Among these gas mixtures, the toluene removal behavior in the SGG atmosphere was very similar to that in the $\mathrm{N}_{2}+\mathrm{CO}+\mathrm{H}_{2}$ atmosphere, and the values of their toluene removal efficiencies were also similar. Thus, the combination of $\mathrm{CO}$ and $\mathrm{H}_{2}$ had a great influence on toluene removal in the SGG atmosphere, and the removal behavior was substantially affected by this combination. Therefore, the low removal performance at low temperatures in the SGG atmosphere is mostly attributed to the 
terminating effect and competitive adsorption induced by CO. In addition, at high temperatures, the lower toluene removal efficiencies in the $\mathrm{N}_{2}+\mathrm{CO}+\mathrm{H}_{2}$ and SGG atmospheres can be attributed to the occurrence of methanation, which will occupy many active sites on the catalyst surface, inhibiting toluene removal reactions.

Fig. $6 \mathrm{~b}$ shows the effects of the gas composition on the tar removal efficiency in the plasma catalytic process. For the $\mathrm{N}_{2}$, $\mathrm{N}_{2}+\mathrm{CO}_{2}$ and $\mathrm{N}_{2}+\mathrm{CO}_{2}+\mathrm{CO}$ atmospheres, the temperature dependence curves of tar removal efficiency were similar to those of toluene removal efficiency, including the same minima temperature $\left(250{ }^{\circ} \mathrm{C}\right)$ and maxima temperature of $400{ }^{\circ} \mathrm{C}$. In the $\mathrm{N}_{2}+\mathrm{CO}+\mathrm{H}_{2}$ and SGG atmospheres, their minima temperature changed to $350{ }^{\circ} \mathrm{C}$, and the highest values $(86.9 \%$ and $64.7 \%$, respectively) were observed at $400{ }^{\circ} \mathrm{C}$. Although the toluene removal efficiencies at $350{ }^{\circ} \mathrm{C}$ were higher than those at $300{ }^{\circ} \mathrm{C}$, high rate of benzene production shifted the changes in the trends of both the $\mathrm{N}_{2}+\mathrm{CO}+\mathrm{H}_{2}$ and SGG atmospheres. Compared to the catalyst alone process, increments of $74.1 \%$ and $49.9 \%$ in the tar removal efficiencies were achieved by the introduction of plasma in the $\mathrm{N}_{2}+\mathrm{CO}+\mathrm{H}_{2}$ and SGG atmospheres at $400{ }^{\circ} \mathrm{C}$, respectively. Obviously, the combination of plasma and the catalyst greatly enhances the tar removal performance of the catalytic process.
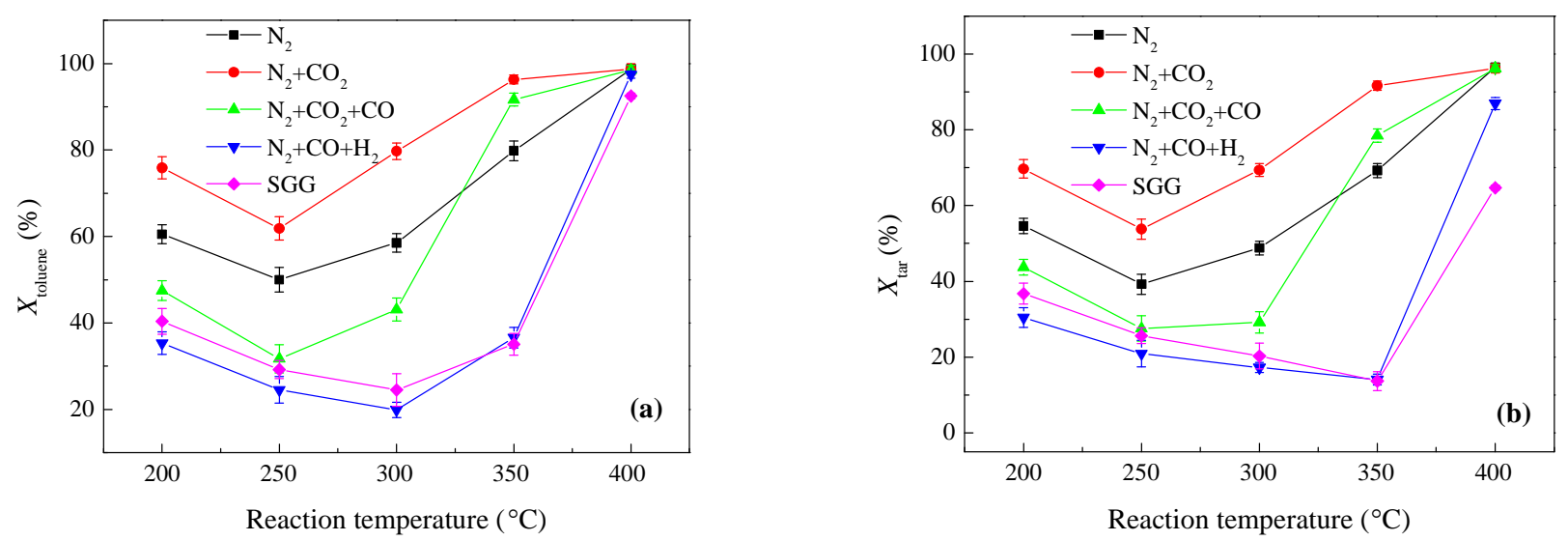

Fig. 6 Effects of gas composition on the toluene removal efficiency (a) and tar removal efficiency (b) as a function of reaction temperature in the plasma catalytic process (reaction conditions: total gas flow rate $=0.06 \mathrm{~m}^{3} / \mathrm{h}$, $\mathrm{specific}$ energy input $=\sim 350 \mathrm{~J} / \mathrm{L}$, and toluene concentration $=600 \mathrm{ppmv})$ 

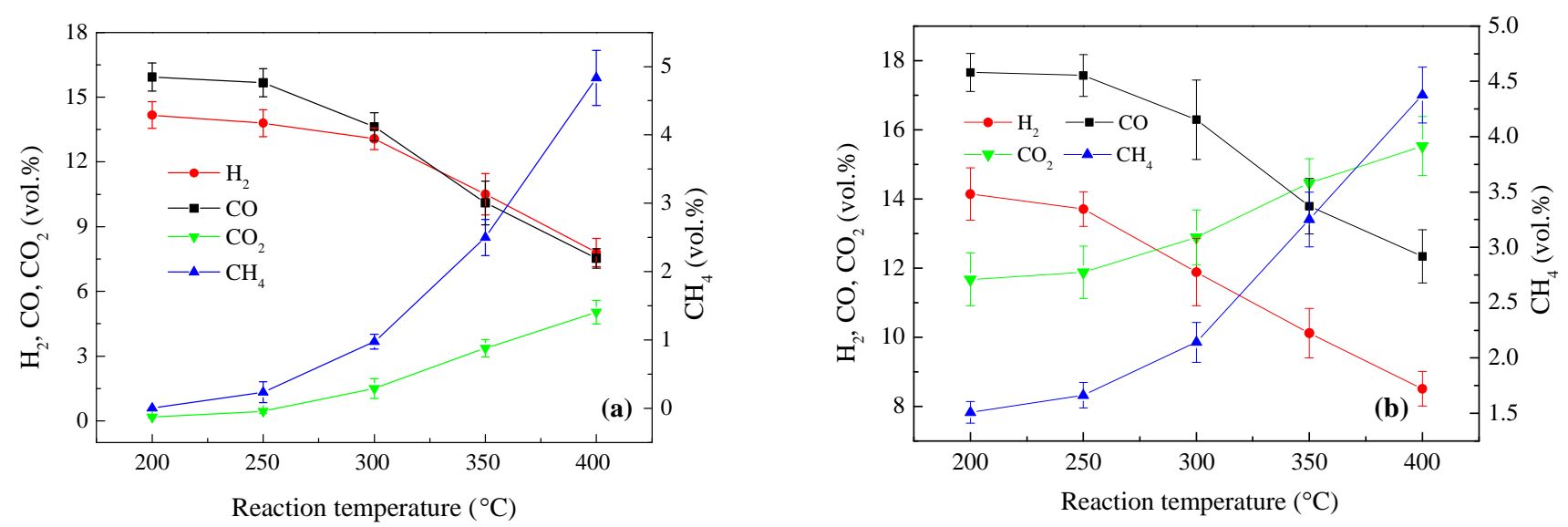

Fig. 7 Concentrations of the main gas components at the outlet under $\mathrm{N}_{2}+\mathrm{CO}+\mathrm{H}_{2}$ (a) and $\mathrm{SGG}$ (b) atmospheres as a function of reaction temperature in the plasma catalytic process (reaction conditions: total gas flow rate $=0.06 \mathrm{~m}^{3} / \mathrm{h}$, specific energy input $=\sim 350 \mathrm{~J} / \mathrm{L}$, and toluene concentration $=600 \mathrm{ppmv})$

\subsection{Reaction mechanism analysis}

The gas composition has a great influence on the removal performance of both the plasma alone and plasma catalytic processes, as described in the previous sections. The effects of the gas composition on the reaction mechanism were also investigated in this work. The liquid byproducts were analyzed qualitatively to clarify the mechanism of toluene degradation. Fig. 8 shows the GC-MS chromatogram of the liquid byproducts obtained in the SGG atmosphere under plasma alone (Fig. 8a) and plasma catalysis treatment (Fig. 8b). Obviously, the number and kinds of liquid byproducts under these two treatments were quite different. This difference indicated that the reaction mechanisms in the plasma alone and plasma catalytic process were different and needed to be analyzed separately.

For the plasma alone process, due to the low toluene removal efficiency at $200{ }^{\circ} \mathrm{C}$, the liquid byproducts generated under different gas mixtures were collected at a high SEI ( $700 \mathrm{~J} / \mathrm{L}$ in this work) to obtain a high concentration of the products. As shown in the previous section, the reaction temperature plays an important role in the plasma catalytic process, and superior removal performances tend to be achieved at higher temperatures. Thus, to obtain the typical byproducts at higher concentrations, the experiments were conducted at a temperature where the toluene removal efficiency should be greater than $80 \%$. 

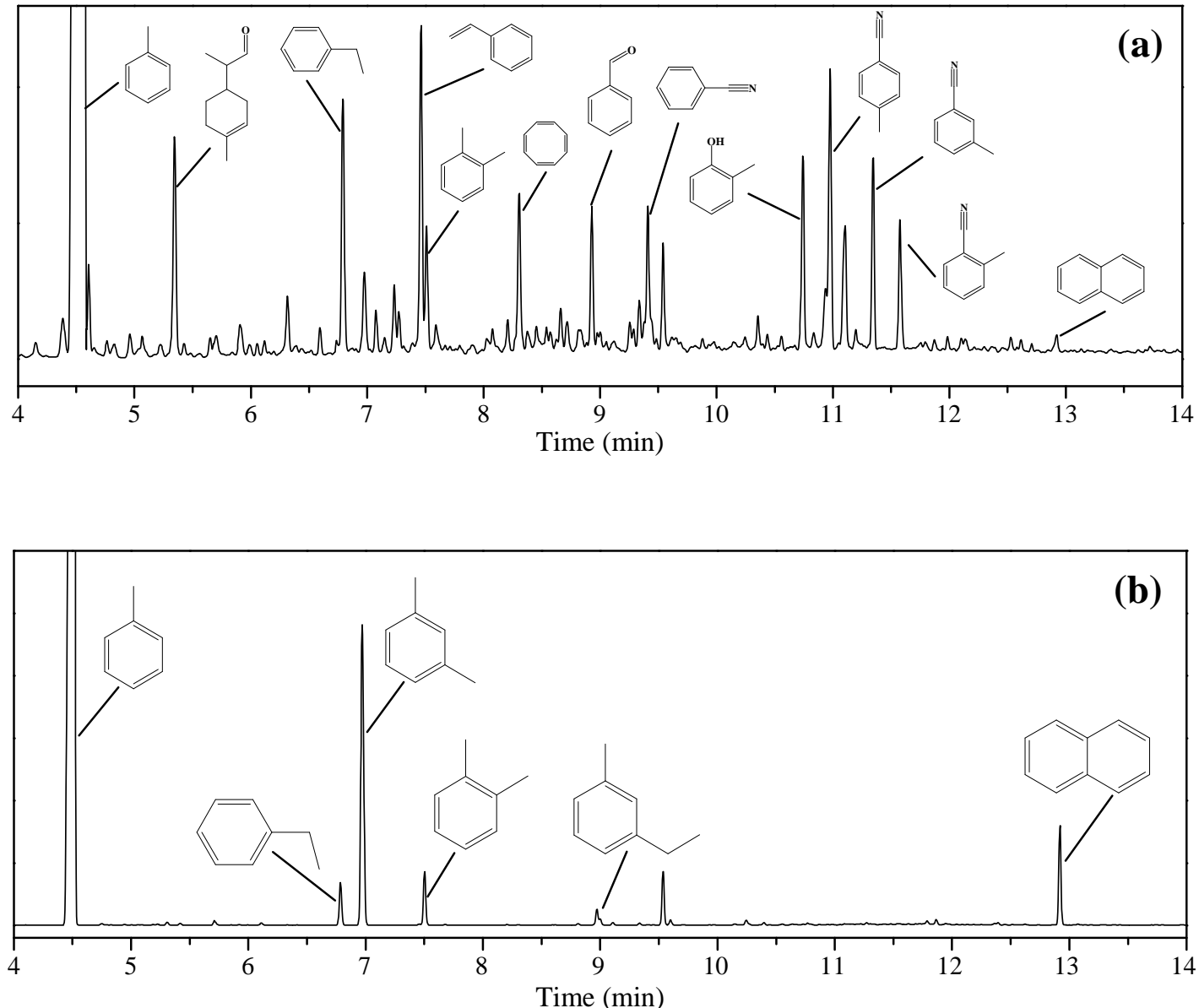

Fig. 8 GC-MS chromatographs of the liquid byproducts in the SGG atmosphere under plasma alone (a) and plasma catalysis treatment (b)

Table 3 lists ten major liquid byproducts of toluene destruction under plasma alone treatment in order of decreasing peak area. The five main liquid byproducts in the plasma catalytic process are ranked in Table 4. As shown in Table 3, the order and type of byproducts obtained in different gas mixtures were different, but some byproducts, such as benzonitrile, styrene and ethylbenzene, were generated under all the gas atmospheres.

In the $\mathrm{N}_{2}$ plasma process, the destruction of toluene can be initiated through two main reaction pathways: $\mathrm{H}$-abstraction of the methyl group and the breaking the benzene ring induced by energetic electrons and $\mathrm{N}_{2}{ }^{*}$, as shown in eqs. 19-22 [22].

$\mathrm{C}_{7} \mathrm{H}_{8} \rightarrow \mathrm{C}_{6} \mathrm{H}_{5} \mathrm{CH}_{2}+\mathrm{H}$

$\mathrm{C}_{7} \mathrm{H}_{8} \rightarrow \mathrm{C}_{6} \mathrm{H}_{4} \mathrm{CH}_{3}+\mathrm{H}$

$\mathrm{C}_{7} \mathrm{H}_{8} \rightarrow \mathrm{C}_{6} \mathrm{H}_{5}+\mathrm{CH}_{3}$

$\mathrm{C}_{7} \mathrm{H}_{8} \rightarrow \mathrm{C}_{2} \mathrm{H}_{2}+\mathrm{C}_{5} \mathrm{H}_{6}$

Remarkably, the aromatic compounds bearing either a $\mathrm{CN}$ group or a group containing two carbons were identified as the major liquid products in the pure $\mathrm{N}_{2}$ atmosphere. The production of these $\mathrm{CN}$-containing compounds suggests the occurrence 
of reaction between $\mathrm{CN}$ radicals and intermediates from toluene degradation. The $\mathrm{H}$-abstraction from $\mathrm{CH}_{3}$ radicals formed via eq. 21 or other intermediates produced $\mathrm{CH}_{2}$ and $\mathrm{CH}$ radicals, which then underwent reactions with $\mathrm{N}$ to form $\mathrm{CN}$ radicals [46].

$\mathrm{CH}_{2}+\mathrm{N} \rightarrow \mathrm{CN}+\mathrm{H}_{2}$

$\mathrm{CH}+\mathrm{N} \rightarrow \mathrm{CN}+\mathrm{H}$

The recombination of $\mathrm{CN}$ radicals with phenyl and methyl-phenyl can produce benzonitrile and 4-methyl-benzonitrile (3methyl-benzonitrile or 2-methyl-benzonitrile), respectively. The recombination of ethynyl radical with methyl-phenyl generates 1-ethynyl-4-methyl-benzene. Moreover, the recombination of the benzyl radical generated from H-abstraction of the toluene methyl group with $\mathrm{CH}_{3}$ and $\mathrm{CH}_{2}$ radicals produces ethylbenzene and styrene, respectively. In addition, indene and naphthalene were also detected, and these compounds were generated from acetylene additions and the ring closure of benzyl and phenyl radicals, respectively [21, 47].

When the background gas was $\mathrm{N}_{2}+\mathrm{CO}_{2}$, O-containing compounds, such as benzaldehyde and 2-methyl-phenol, were detected as the main liquid compounds, which suggests that the $\mathrm{O}$ radicals derived from $\mathrm{CO}_{2}$ (eq. 5) participated in the toluene removal reactions. The combination of $\mathrm{OH}$ radical and methyl-phenyl radicals produced 2-methyl-phenol and 3-methyl-phenol. In addition, benzaldehyde and benzyl alcohol might be formed from the reactions between benzyl and $\mathrm{OH}$ radicals [22]. $\mathrm{OH}$ radicals can be generated by the following reactions $[46,48]$.

$\mathrm{O}+\mathrm{H}+\mathrm{M} \rightarrow \mathrm{OH}+\mathrm{M}$

$\mathrm{O}+\mathrm{C}_{7} \mathrm{H}_{8} \rightarrow \mathrm{OH}+\mathrm{C}_{6} \mathrm{H}_{5} \mathrm{CH}_{2}$

In addition to $\mathrm{O}$-containing compounds, compounds bearing $\mathrm{CN}$ groups or groups containing two carbons, such as benzonitrile and styrene, identified in the $\mathrm{N}_{2}$ atmosphere were also detected in this case.

In the $\mathrm{N}_{2}+\mathrm{CO}_{2}+\mathrm{CO}$ atmosphere, the $\mathrm{O}$-containing compounds and the compounds containing a $\mathrm{CN}$ group or groups containing two carbons were generated under plasma alone treatment. Compared to the previously discussed $\mathrm{N}_{2}+\mathrm{CO}_{2}$ atmosphere, the position of O-containing compounds moves backwards, as shown in Table 3. This phenomenon is attributed to the consumption of $\mathrm{CO}$ to $\mathrm{O}$ radicals (eq. 13) and $\mathrm{OH}$ radicals[48], leading to a decrease in the $\mathrm{OH}$ radical concentration. In the case of the $\mathrm{N}_{2}+\mathrm{CO}+\mathrm{H}_{2}$ atmosphere, the absence of $\mathrm{CO}_{2}$ decreases the amounts and variety of O-containing compounds generated. Although $\mathrm{O}$ radicals can be obtained by the dissociation of $\mathrm{CO}$, the bond dissociation energy of $\mathrm{CO}(11 \mathrm{eV})$ is twice the bond dissociation energy of $\mathrm{CO}_{2}(5.5 \mathrm{eV})$, making it significantly harder to break these bonds to produce $\mathrm{O}$ radicals [41]. In addition to some of the aromatic products mentioned above, $\alpha, 4$-dimethyl-3-cyclohexene-1-acetaldehyde and 1,3,5,7cyclooctatetraene were detected in this gas mixture. Due to the presence of bulk $\mathrm{H}_{2}$ in the atmosphere, toluene might be 
eliminated by hydrogenation reactions, leading to the formation of 1-methyl-1-cyclohexene. Moreover, the reaction of $\mathrm{H}_{2}$, $\mathrm{CO}$ and acetylene generated from the ring cleavage of toluene via eq. 22 could produce propionaldehyde [49]. $\alpha, 4-\mathrm{Dimethyl-}$ 3-cyclohexene-1-acetaldehyde might be formed by the reaction of 1-methyl-1-cyclohexene and propionaldehyde. The production of $\alpha$,4-dimethyl-3-cyclohexene-1-acetaldehyde depends on the presence of both $\mathrm{H}_{2}$ and $\mathrm{CO}$; thus, it cannot be detected in the above three gas mixtures. 1,3,5,7-Cyclooctatetraene could be generated through the cyclization of four biradical $\mathrm{HC}=\mathrm{CH}$. For the SGG atmosphere, styrene, 2-methyl-benzonitrile and ethylbenzene were identified as the major byproducts, and all liquid products can be found in the cases of the above four gas mixture because it contains all the gas components.

Notably, the peak areas of these byproducts, which have molecular weights larger than that of toluene, were several orders of magnitude lower than that of the remaining toluene, which means that a very small proportion of the toluene was converted to higher molecular weight products. Moreover, this phenomenon can be observed in both the plasma alone process and the plasma catalytic process for all gas mixtures. Therefore, the main reaction pathway for toluene removal in the plasma alone process was via reactions of toluene and aromatic intermediates generated from the degradation of toluene, e.g., phenyl and benzyl, with energetic electrons and active species such as $\mathrm{N}_{2} *$ and $\mathrm{O}$ radicals, which generated gaseous products. For example, acetylene, a main gaseous product, was detected in all gas atmospheres. Additionally, as a much less predominant possible degradation pathway, some aromatic intermediates may ultimately react with fragments or radicals, such as $\mathrm{CN}, \mathrm{CH}_{3}$ and $\mathrm{OH}$ radicals, and the kinds and concentrations of these species rely on the composition of the background gas; these reactions would form stable liquid byproducts.

According to the above description, the possible reaction pathways for toluene removal under plasma treatment are summarized in Fig. 9. In the plasma alone process, benzyl, phenyl, and methyl-phenyl radicals as well as radicals of fragments such as $\mathrm{CH}_{3}, \mathrm{CH}_{2}$ and $\mathrm{H}$ can be generated by collisions between toluene and energetic electrons or excited species. Moreover, the cleavage of the benzene ring of toluene can form acetylene. Multiple reactions among these aforementioned species can generate aromatic products, including benzene, styrene, 1-ethynyl-4-methyl-benzene, ethylbenzene, 1,2-dimethyl-benzene, indene and naphthalene. $\mathrm{CN}$ and $\mathrm{NH}_{2}$ radicals can be formed in the plasma process when $\mathrm{N}_{2}$ is present in the background gas. The reactions between $\mathrm{CN} / \mathrm{NH}_{2}$ radicals and aromatic intermediates derived from toluene degradation could produce aniline and $\mathrm{CN}$-containing compounds such as benzonitrile and 4-methyl-benzonitrile, as shown in Fig. 9. When $\mathrm{CO}_{2}$ is present in the background gas, $\mathrm{OH}$ radicals can react with aromatic intermediates to form O-containing compounds, such as benzaldehyde and 2-methyl-phenol. There are two unique liquid products, 1,3,5,7-cyclooctatetraene and $\alpha, 4-d i m e t h y l-3-$ cyclohexene-1-acetaldehyde, that were detected only when the background gas contained $\mathrm{CO}$ and $\mathrm{H}_{2}$. 1,3,5,7Cyclooctatetraene can be formed by the combination of four biradical $\mathrm{HC}=\mathrm{CH}$. The reaction of propionaldehyde and 1- 


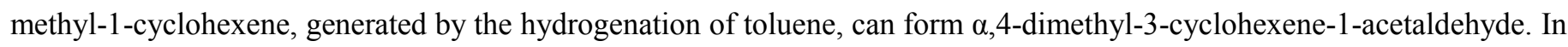
addition, $\mathrm{H}$ radicals derived from the $\mathrm{H}$-abstraction of $\mathrm{CH}_{3}$, toluene and other fragments could combine to produce $\mathrm{H}_{2}$.

Table 3 Major liquid byproducts of toluene removal in different gas mixtures under plasma alone treatment






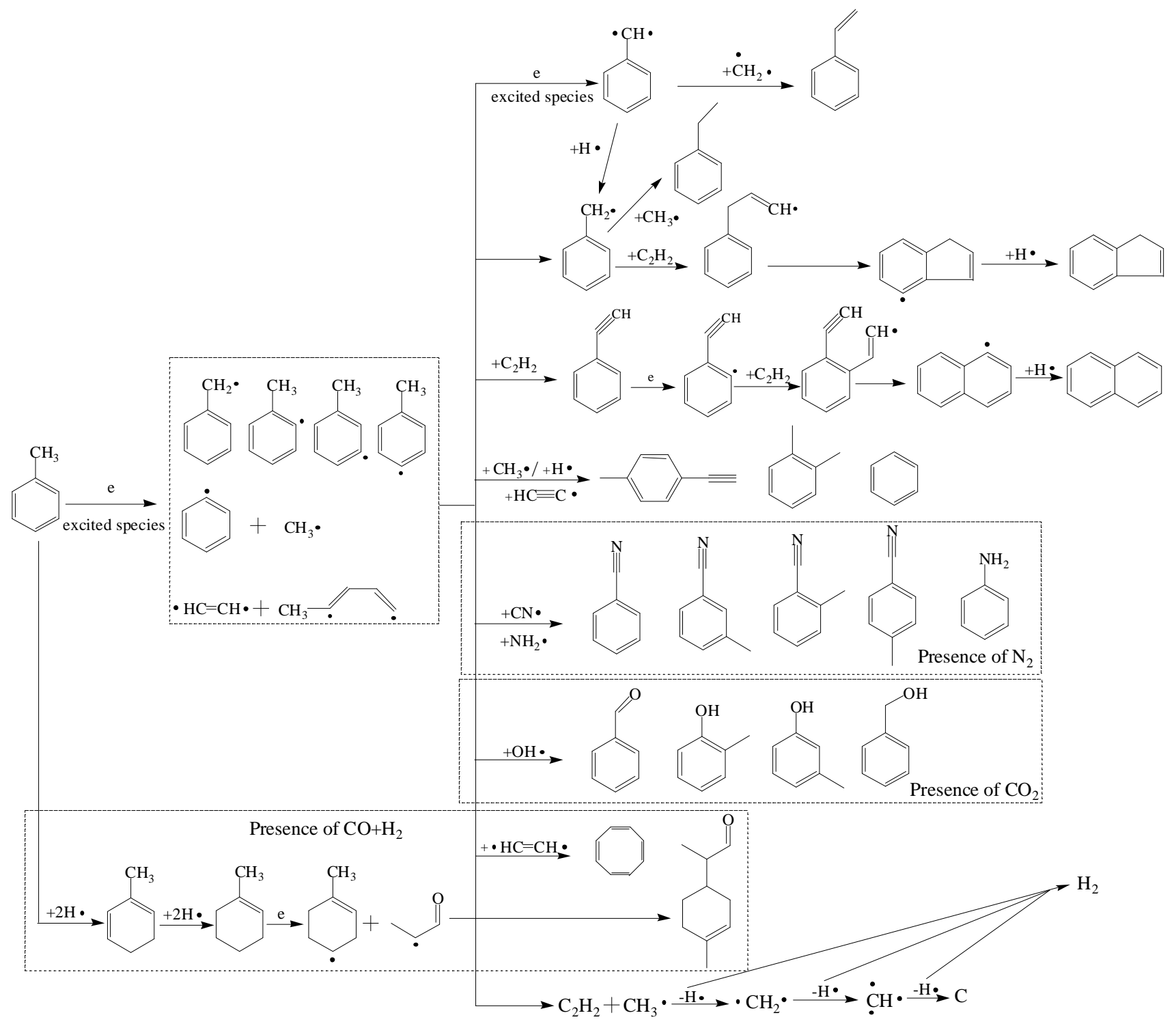

Fig. 9 Possible reaction pathways for toluene degradation in the plasma alone process.

When toluene removal was carried out in a plasma catalytic process, the major liquid byproducts were distinct from those obtained from the plasma alone process, as shown in Table 4. Clearly, compounds containing $\mathrm{CN}$ or $\mathrm{OH}$ groups were not detected in all the gas mixtures under plasma catalysis treatment. Due to the low plasma intensity induced by high temperatures, the electrons do not have enough energy to break the bonds of $\mathrm{N}_{2}$ or $\mathrm{CO}_{2}$ to form radicals such as those of $\mathrm{CN}$ and $\mathrm{OH}$. However, the dissociation energies of the $\mathrm{C}-\mathrm{H}$ bonds in methyl groups, the $\mathrm{C}-\mathrm{C}$ bonds between the methyl and benzene ring and the $\mathrm{C}-\mathrm{H}$ bonds in the aromatic ring are smaller than those of the bonds in $\mathrm{N}_{2}$ and $\mathrm{CO}_{2}$, and hence, some fragments or radicals such as phenyl, benzyl and $\mathrm{CH}_{3}$ could be catalytically generated or by reactions with electrons and excited species [22]. Therefore, although $\mathrm{CN}$-containing and O-containing compounds were not observed, aromatic compounds with one or serval $\mathrm{CH}_{3}$-substituents or $\mathrm{C}_{2} \mathrm{H}_{5}$-substituents were identified as major byproducts in the plasma catalytic process. 
Table 4 shows that the liquid byproducts in the $\mathrm{N}_{2}+\mathrm{CO}_{2}$ atmosphere were significantly different from those obtained in other gas atmospheres. However, when $\mathrm{CO}_{2}$ was mixed with $\mathrm{CO}$ and $\mathrm{H}_{2}$, the effect of $\mathrm{CO}_{2}$ on the composition of the major liquid products became negligible, which was concluded by the fact that the $\mathrm{N}_{2}+\mathrm{CO}+\mathrm{H}_{2}$ and $\mathrm{SGG}$ atmospheres have the same main liquid byproducts, as shown in Table 4. A similar phenomenon can be seen in terms of the removal performances under different gas atmospheres; the toluene removal efficiency in the $\mathrm{N}_{2}+\mathrm{CO}+\mathrm{H}_{2}$ atmosphere was quite similar to that in the SGG atmosphere over the temperature range of $200-400{ }^{\circ} \mathrm{C}$. In addition, the liquid products from the pure $\mathrm{N}_{2}$ atmosphere were similar to those in the $\mathrm{N}_{2}+\mathrm{CO}+\mathrm{H}_{2}$ and $\mathrm{SGG}$ atmospheres.

As mentioned above, the concentrations of these liquid byproducts were significantly lower than that of residual toluene in the plasma catalytic process. Hence, the majority of the toluene was decomposed through catalytic reactions or reactions with energetic electrons and reactive species to form low-molecular-weight products such as benzene identified at high concentrations in these experiments. Moreover, benzene could be further decomposed into gaseous products. The other possible route of toluene removal may involve reactions of aromatic intermediates with fragments/radicals or gaseous products, such as $\mathrm{CH}_{3}$ or $\mathrm{C}_{2} \mathrm{H}_{2}$, to form liquid products.

The possible reaction pathways of toluene removal under plasma catalysis treatment are schematically shown in Fig. 10. In the plasma catalytic process, the $\mathrm{C}-\mathrm{H}$ bonds in methyl groups, the $\mathrm{C}-\mathrm{C}$ bonds between the methyl and benzene ring, and the C-H bonds in the benzene ring can be cleaved to form benzyl, phenyl and methyl-phenyl species, respectively. Phenyl radicals can react with acetylene and $\mathrm{H}$ radicals to form naphthalene and benzene, respectively, and benzene can be further decomposed to form $\mathrm{H}_{2}$ and CO. Byproducts such as ethylbenzene, 1-ethyl-3-methyl-benzene and 1,3-dimethyl-benzene (1,2dimethyl-benzene) could be generated through the reactions of benzyl or methyl-phenyl species with $\mathrm{CH}_{3}$ or $\mathrm{C}_{2} \mathrm{H}_{5}$ radicals. In addition, $\mathrm{H}$-abstraction from the benzene ring of these aforementioned byproducts can also occur, and the generated species can then react with $\mathrm{CH}_{3}$ radicals to form other compounds, such as 1,2,3,5-tetramethyl-benzene and 4-ethyl-1,2-dimethylbenzene. Toluene can also be decomposed by the dissociation of $\mathrm{C}-\mathrm{C}$ bonds in the aromatic ring to produce biradical $\mathrm{HC}=\mathrm{CH}$ and methyl-cyclobutadiene, eventually forming acetylene, $\mathrm{CO}$ and $\mathrm{H}_{2}$. 


\begin{tabular}{|c|c|c|c|c|c|}
\hline Gas mixtures & & 2 & 3 & 4 & \\
\hline \multicolumn{6}{|l|}{$\mathrm{N}_{2}$} \\
\hline & $\begin{array}{l}\text { 1,3-Dimethyl- } \\
\text { benzene }\end{array}$ & Naphthalene & $\begin{array}{l}\text { 1,2-Dimethyl- } \\
\text { benzene }\end{array}$ & Ethylbenzene & $\begin{array}{c}\text { 1,2,3,5-Tetramethyl- } \\
\text { benzene }\end{array}$ \\
\hline \multicolumn{6}{|l|}{$\mathrm{N}_{2}+\mathrm{CO}_{2}$} \\
\hline & $\begin{array}{c}1,2,3,5- \\
\text { Tetramethyl- } \\
\text { benzene }\end{array}$ & $\begin{array}{l}\text { 1,3-Dimethyl- } \\
\text { benzene }\end{array}$ & $\begin{array}{c}1,2,4,5- \\
\text { Tetramethyl- } \\
\text { benzene }\end{array}$ & Ethylbenzene & $\begin{array}{l}\text { 4-Ethyl-1,2-dimethyl- } \\
\text { benzene }\end{array}$ \\
\hline \multicolumn{6}{|l|}{$\mathrm{N}_{2}+\mathrm{CO}_{2}+\mathrm{CO}$} \\
\hline & $\begin{array}{l}\text { 1,3-Dimethyl- } \\
\text { benzene }\end{array}$ & $\begin{array}{c}\text { 1,2,3,5- } \\
\text { Tetramethyl- } \\
\text { benzene }\end{array}$ & $\begin{array}{c}1,2,4,5- \\
\text { Tetramethyl- } \\
\text { benzene }\end{array}$ & Naphthalene & Ethylbenzene \\
\hline \multicolumn{6}{|l|}{$\mathrm{N}_{2}+\mathrm{CO}+\mathrm{H}_{2}$} \\
\hline & $\begin{array}{c}\text { 1,3-Dimethyl- } \\
\text { benzene }\end{array}$ & Naphthalene & $\begin{array}{c}\text { 1,2-Dimethyl- } \\
\text { benzene }\end{array}$ & Ethylbenzene & $\begin{array}{l}\text { 1-Ethyl-3-methyl- } \\
\text { benzene }\end{array}$ \\
\hline \multicolumn{6}{|l|}{ SGG } \\
\hline & $\begin{array}{c}\text { 1,3-Dimethyl- } \\
\text { benzene }\end{array}$ & Naphthalene & $\begin{array}{c}\text { 1,2-Dimethyl- } \\
\text { benzene }\end{array}$ & Ethylbenzene & $\begin{array}{l}\text { 1-Ethyl-3-methyl- } \\
\text { benzene }\end{array}$ \\
\hline
\end{tabular}




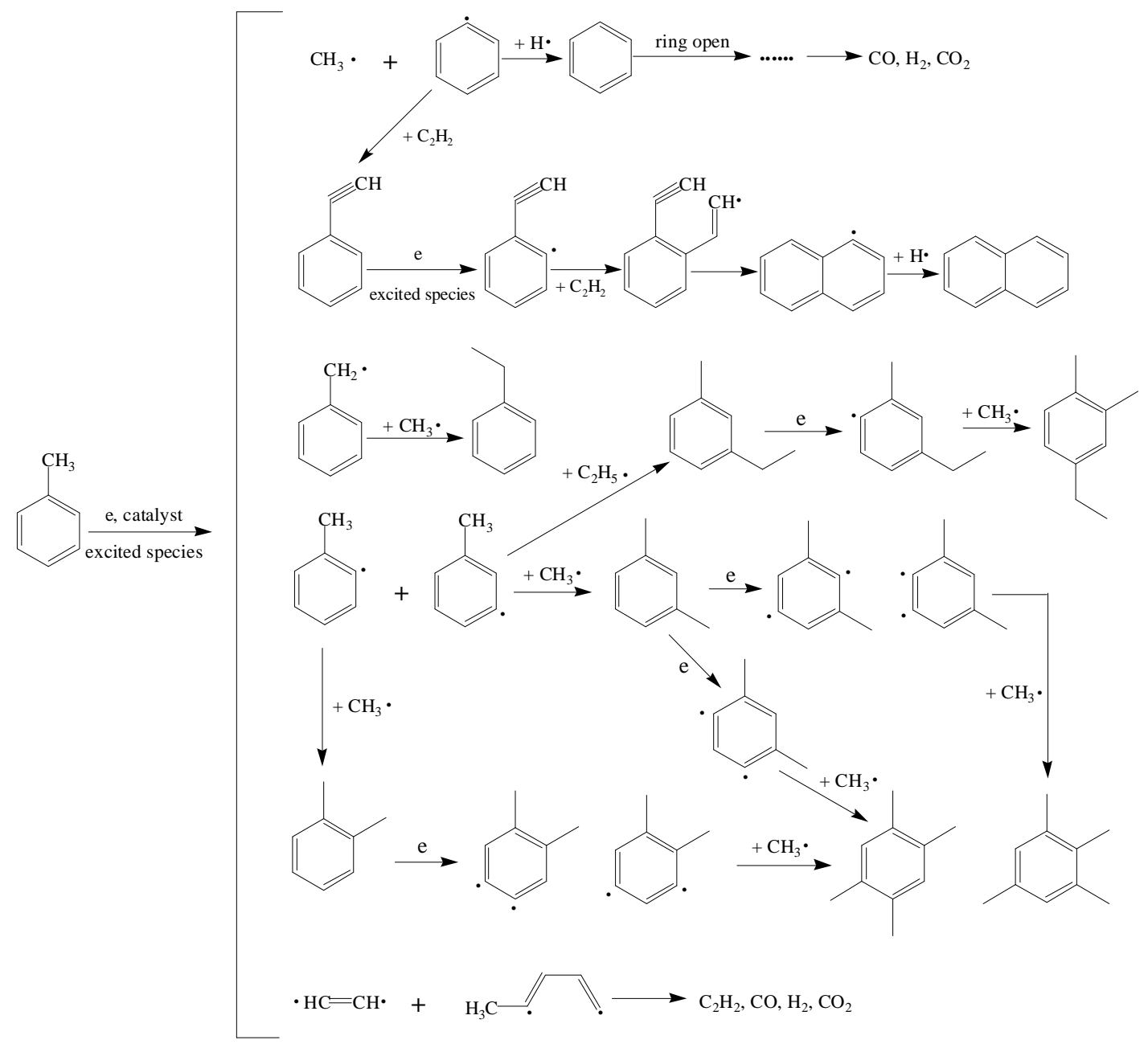

Fig. 10 Possible reaction pathways for toluene degradation in the plasma catalytic process.

\section{Conclusions}

In this study, the removal of toluene as a biomass tar surrogate was carried out via a plasma alone process, a catalyst alone process and a plasma catalytic process. The effects of the major components of the gasification fuel gas on toluene removal were evaluated by selecting five typical gas combinations, $\mathrm{N}_{2}, \mathrm{~N}_{2}+\mathrm{CO}_{2}, \mathrm{~N}_{2}+\mathrm{CO}_{2}+\mathrm{CO}, \mathrm{N}_{2}+\mathrm{CO}+\mathrm{H}_{2}$ and $\mathrm{SGG}$, as the carrier gases. Moreover, based on the analysis of the gas products and liquid products, the possible reaction pathways in the plasma process and plasma catalytic process were proposed.

The gas composition has a substantial influence on toluene removal in both the plasma process and the plasma catalytic process. In the plasma alone process, $\mathrm{N}_{2} *$ was the most effective species for tar destruction, and the best toluene removal efficiency was obtained in the $\mathrm{N}_{2}$ atmosphere. The addition of other gaseous components decreases the $\mathrm{N}_{2}$ concentration and introduces species, such as $\mathrm{CO}$ and $\mathrm{O}$ radicals, that can terminate $\mathrm{N}_{2} *$, decreasing the $\mathrm{N}_{2} *$ concentration and inhibiting the removal of toluene. However, toluene cannot be effectively removed by the plasma alone treatment, as the highest toluene removal efficiency was $50.5 \%$. Toluene can be effectively removed by combining the plasma and the catalyst into a hybrid reactor, and the highest toluene removal efficiencies under all the gas atmospheres were above $90 \%$. In the plasma catalytic 
process, $\mathrm{CO}_{2}$ plays a positive role in toluene removal, but the positive effect will be negated and a detrimental effect is observed when $\mathrm{CO}_{2}$ coexists with $\mathrm{CO}$ and $\mathrm{H}_{2}$ in the gas mixture. The effect of terminating $\mathrm{N}_{2}{ }^{*}$, the competitive adsorption with reactants and the occurrence of methanation induced by $\mathrm{CO}$ severely inhibit the removal of toluene, and hence $\mathrm{CO}$ was regarded as a major inhibiter of the toluene removal process. In addition, small amounts of liquid byproducts were detected after the plasma alone and the plasma catalytic process, and these species were formed by reactions between aromatic intermediates and fragments or radicals. Toluene is mainly removed through catalytic reactions or reactions with energetic electrons and active species to form low-molecular-weight products.

\section{AUTHOR INFORMATION}

Corresponding Author

*E-mail: xiejj@ms.giec.ac.cn.

\section{Notes}

The authors declare no competing financial interest.

\section{ACKNOWLEDGEMENTS}

This wok was supported by the National Natural Science Foundation of China (Grant No. 51576200, 51811530317), the Natural Science Foundation of Guangdong Province of China (Grant No. 2017B030308002) and Royal Society International Exchanges 2017 Cost Share (China) (IECINSFCl170654).

\section{References}

[1] McKendry P. Energy production from biomass (part 2): conversion technologies. Bioresource Technology 2002;83(1):47-54.

[2] Deshmukh R, Jacobson A, Chamberlin C, Dan K. Thermal gasification or direct combustion? Comparison of advanced cogeneration systems inthe sugarcane industry. Biomass \& Bioenergy 2013;55(55):163-74.

[3] Kumar A, Demirel Y, Jones DD, Hanna MA. Optimization and economic evaluation of industrial gas production and combined heat and power generation from gasification of corn stover and distillers grains. Bioresource Technology 2010;101(10):3696-701.

[4] Leibbrandt NH, Aboyade AO, Knoetze JH, Görgens JF. Process efficiency of biofuel production via gasification and FischerTropsch synthesis. Fuel 2013;109(7):484-92.

[5] Han J, Kim H. The reduction and control technology of tar during biomass gasification/pyrolysis: An overview. Renewable \& Sustainable Energy Reviews 2008;12(2):397-416.

[6] Li CS, Suzuki K. Tar property, analysis, reforming mechanism and model for biomass gasification-An overview. Renewable \& Sustainable Energy Reviews 2009;13(3):594-604.

[7] Anis S, Zainal ZA. Tar reduction in biomass producer gas via mechanical, catalytic and thermal methods: A review. Renewable and Sustainable Energy Reviews 2011;15(5):2355-77.

[8] Chen Y, Luo Y-h, Wu W-g, Su Y. Experimental Investigation on Tar Formation and Destruction in a Lab-Scale Two-Stage Reactor. Energy \& Fuels 2009;23(9):4659-67.

[9] Shen Y, Yoshikawa K. Recent progresses in catalytic tar elimination during biomass gasification or pyrolysis-A review. Renewable \& Sustainable Energy Reviews 2013;21:371-92.

[10] Harling AM, Glover DJ, Whitehead JC, Zhang K. Novel Method for Enhancing the Destruction of Environmental Pollutants by the Combination of Multiple Plasma Discharges. Environmental Science \& Technology 2008;42(12):4546-50. 
[11] Kim H-H. Nonthermal Plasma Processing for Air-Pollution Control: A Historical Review, Current Issues, and Future Prospects. Plasma Processes and Polymers 2004;1(2):91-110.

[12] Najafpoor AA, Jonidi Jafari A, Hosseinzadeh A, Khani Jazani R, Bargozin H. Optimization of non-thermal plasma efficiency in the simultaneous elimination of benzene, toluene, ethyl-benzene, and xylene from polluted airstreams using response surface methodology. Environmental Science and Pollution Research 2018;25(1):233-41.

[13] Liu L, Wang Q, Song J, Yang X, Sun Y. Dry reforming of model biomass pyrolysis products to syngas by dielectric barrier discharge plasma. International Journal of Hydrogen Energy 2018;43(22):10281-93.

[14] Liu L, Wang Q, Song J, Ahmad S, Yang X, Sun Y. Plasma-assisted catalytic reforming of toluene to hydrogen rich syngas. Catalysis Science \& Technology 2017;7:4216-31

[15] Saleem F, Zhang K, Harvey A. Role of CO2 in the Conversion of Toluene as a Tar Surrogate in a Nonthermal Plasma Dielectric Barrier Discharge Reactor. Energy \& Fuels 2018;32(4):5164-70.

[16] Saleem F, Zhang K, Harvey A. Plasma-assisted decomposition of a biomass gasification tar analogue into lower hydrocarbons in a synthetic product gas using a dielectric barrier discharge reactor. Fuel 2019;235:1412-9.

[17] Saleem F, Zhang K, Harvey A. Temperature dependence of non-thermal plasma assisted hydrocracking of toluene to lower hydrocarbons in a dielectric barrier discharge reactor. Chemical Engineering Journal 2019;356:1062-9.

[18] Liu L, Wang Q, Ahmad S, Yang X, Ji M, Sun Y. Steam reforming of toluene as model biomass tar to H2-rich syngas in a DBD plasma-catalytic system. Journal of the Energy Institute 2018;91(6):927-39.

[19] Nair SA, Pemen AJM, Yan K, van Gompel FM, van Leuken HEM, van Heesch EJM, et al. Tar removal from biomassderived fuel gas by pulsed corona discharges. Fuel Processing Technology 2003;84(1-3):161-73.

[20] Pemen AJM, Nair SA, Yan K, van Heesch EJM, Ptasinski KJ, Drinkenburg AAH. Pulsed corona discharges for tar removal from biomass derived fuel gas. Plasmas and Polymers 2003;8(3):209-24.

[21] Zhu F, Li X, Zhang H, Wu A, Yan J, Ni M, et al. Destruction of toluene by rotating gliding arc discharge. Fuel 2016;176:7885 .

[22] Liu S, Mei D, Wang L, Tu X. Steam reforming of toluene as biomass tar model compound in a gliding arc discharge reactor. Chemical Engineering Journal 2017;307:793-802.

[23] Nunnally T, Tsangaris A, Rabinovich A, Nirenberg G, Chernets I, Fridman A. Gliding arc plasma oxidative steam reforming of a simulated syngas containing naphthalene and toluene. International Journal of Hydrogen Energy 2014;39(23):11976-89.

[24] Wnukowski M, Jamróz P. Microwave plasma treatment of simulated biomass syngas: Interactions between the permanent syngas compounds and their influence on the model tar compound conversion. Fuel Processing Technology 2018;173:229-42.

[25] Sun J, Wang Q, Wang W, Wang K. Study on the synergism of steam reforming and photocatalysis for the degradation of Toluene as a tar model compound under microwave-metal discharges. Energy 2018;155:815-23.

[26] Jamróz P, Kordylewski W, Wnukowski M. Microwave plasma application in decomposition and steam reforming of model tar compounds. Fuel Processing Technology 2018;169:1-14.

[27] Van Durme J, Dewulf J, Leys C, Van Langenhove H. Combining non-thermal plasma with heterogeneous catalysis in waste gas treatment: A review. Applied Catalysis B: Environmental 2008;78(3-4):324-33.

[28] Wang Q, Yan BH, Jin Y, Cheng Y. Dry Reforming of Methane in a Dielectric Barrier Discharge Reactor with Ni/Al2O3 Catalyst: Interaction of Catalyst and Plasma. Energy \& Fuels 2009;23(8):4196-201.

[29] Tu X, Whitehead JC. Plasma-catalytic dry reforming of methane in an atmospheric dielectric barrier discharge: Understanding the synergistic effect at low temperature. Applied Catalysis B: Environmental 2012;125(Supplement C):439-48.

[30] Zoran F, John JC. Microdischarge behaviour in the silent discharge of nitrogen - oxygen and water - air mixtures. Journal of Physics D: Applied Physics 1997;30(5):817-25.

[31] Goujard V, Tatibouët JM, Batiot-Dupeyrat C. Carbon Dioxide Reforming of Methane Using a Dielectric Barrier Discharge Reactor: Effect of Helium Dilution and Kinetic Model. Plasma Chemistry \& Plasma Processing 2011;31(2):315-25.

[32] Nair SA, Pemen AJM, Yan K, van Heesch EJM, Ptasinski KJ, Drinkenburg AAH. Chemical processes in tar removal from biomass derived fuel gas by pulsed corona discharges. Plasma Chemistry and Plasma Processing 2003;23(4):665-80.

[33] Bityurin VA, Filimonova EA, Naidis GV. Simulation of Naphthalene Conversion in Biogas Initiated by Pulsed Corona Discharges. Ieee Transactions on Plasma Science 2009;37(6):911-9. 
[34] Simell PA, Hepola JO, Krause AOI. Effects of gasification gas components on tar and ammonia decomposition over hot gas cleanup catalysts. Fuel 1997;76(12):1117-27.

[35] Devi L, Ptasinski KJ, Janssen FJJG. Decomposition of Naphthalene as a Biomass Tar over Pretreated Olivine: Effect of Gas Composition, Kinetic Approach, and Reaction Scheme. Industrial \& Engineering Chemistry Research 2005;44(24):9096-104.

[36] Hasler P, Nussbaumer T. Gas cleaning for IC engine applications from fixed bed biomass gasification. Biomass and Bioenergy 1999;16(6):385-95.

[37] Xu B, Xie J, Zhan H, Yin X, Wu C, Liu H. Removal of Toluene as a Biomass Tar Surrogate in a Catalytic Nonthermal Plasma Process. Energy \& Fuels 2018;32(10):10709-19.

[38] Abdelaziz AA, Seto T, Abdel-Salam M, Otani Y. Influence of nitrogen excited species on the destruction of naphthalene in nitrogen and air using surface dielectric barrier discharge. Journal of Hazardous Materials 2013;246-247:26-33.

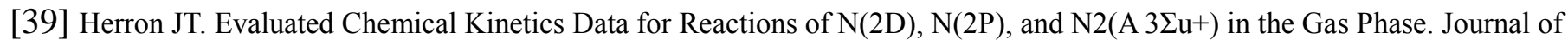
Physical \& Chemical Reference Data 1999;28(5):1453-83.

[40] Zheng C, Zhu X, Gao X, Liu L, Chang Q, Luo Z, et al. Experimental study of acetone removal by packed-bed dielectric barrier discharge reactor. Journal of Industrial and Engineering Chemistry 2014;20(5):2761-8.

[41] Darwent BB. Bond dissociation energies in simple molecules. NBSDS-NBS 31, National Bureau of Standards, Wasshington, DC, 1970; p. 23.

[42] Neyts EC, Bogaerts A. Understanding plasma catalysis through modelling and simulation-a review. Journal of Physics DApplied Physics 2014;47(22):224010

[43] Blackbeard T, Demidyuk V, Hill SL, Whitehead JC. The Effect of Temperature on the Plasma-Catalytic Destruction of Propane and Propene: A Comparison with Thermal Catalysis. Plasma Chemistry and Plasma Processing 2009;29(6):411-9.

[44] Harling AM, Kim H-H, Futamura S, Whitehead JC. Temperature Dependence of Plasma-Catalysis Using a Nonthermal, Atmospheric Pressure Packed Bed; the Destruction of Benzene and Toluene. J. Phys. Chem. C 2007;111(13):5090-5.

[45] Chen T, Liu H, Shi P, Chen D, Song L, He H, et al. CO2 reforming of toluene as model compound of biomass tar on Ni/Palygorskite. Fuel 2013;107(Supplement C):699-705.

[46] Yu L, Li XD, Tu X, Wang Y, Lu SY, Yan JH. Decomposition of Naphthalene by dc Gliding Arc Gas Discharge. Journal of Physical Chemistry A 2010;114(1):360-8.

[47] Mcenally CS, Pfefferle LD. Experimental Assessment of Naphthalene Formation Mechanisms in Non-Premixed Flames. Combustion Science \& Technology 1997;128(1-6):257-78.

[48] Nair SA, Yan K, Pemen AJM, van Heesch EJM, Ptasinski KJ, Drinkenburg AAH. Tar removal from biomass-derived fuel gas by pulsed corona discharges. A chemical kinetic study. Industrial \& Engineering Chemistry Research 2004;43(7):1649-58. [49] Massoudi R, Kim JH, King RB, King AD. Homogeneous catalysis of the Reppe reaction with iron pentacarbonyl: the production of propionaldehyde and 1-propanol from ethylene. Journal of the American Chemical Society 1987;109(24):7428-33. 